\title{
"Engaging with Engagement": A New Communications Strategy That Provides Coherence Making Companies More Competitive and Public Institutions More Agile and Accessible
}

\author{
Chris D. Beaumont ${ }^{1}$, Darrell Berry ${ }^{2}$, John Ricketts ${ }^{2}$ \\ ${ }^{1}$ Institute for Future Initiatives, LifeStyle by Design, The University of Tokyo, Tokyo, Japan \\ ${ }^{2}$ Significance Systems, Sydney, Australia \\ Email: cbeaumont@g.ecc.u-tokyo.ac.jp
}

How to cite this paper: Beaumont, C. D., Berry, D., \& Ricketts, J. (2021). "Engaging with Engagement": A New Communications Strategy That Provides Coherence Making Companies More Competitive and Public Institutions More Agile and Accessible. Advances in Journalism and Communication, 9, 161-195.

https://doi.org/10.4236/ajc.2021.94013

Received: September 9, 2021

Accepted: December 6, 2021

Published: December 9, 2021

Copyright $\odot 2021$ by author(s) and Scientific Research Publishing Inc. This work is licensed under the Creative Commons Attribution International License (CC BY 4.0).

http://creativecommons.org/licenses/by/4.0/

\begin{abstract}
Social media and social sharing have enabled narratives to readily go viral and influence people's attitudes and behaviour. We leverage Big Data and AI technology to identify specific content (topics, triggers, media channels...) that drive past and future outcomes. With trust in traditional institutions at an all-time low, the ability to connect and communicate new ways of healthy living, by understanding what is important to people is critical to bring about behavioral change, at scale. This paper explores some lifestyle narratives during a period of extraordinary uncertainty due to COVID-19, in the different cultures of the UK and Japan. Appreciating what is important to people aids policy makers and educators to engage with their audiences in a relevant evocative and effective manner. The narratives that are shaping our increasingly, digital lives can lead to new lifestyle behaviours that can enhance people's QOL (Quality of Life). What is critical, especially, during changing times, is a need to ensure that your story maintains a relevance in content and emotion, to ensure you resonate and your message is embraced.
\end{abstract}

\section{Keywords}

Social, Narratives, Empowerment, Affect, Engagement, Informed Choice, Trust, Health Literacy 


\section{Context for Change}

\subsection{Evolving Health}

We live in an Accelerating Age of change where it is not only the rate of change that is new but that the nature of change itself is changing. No category is immune to transformational change and no leading institution or corporation is too big to fail. Healthcare is increasingly a focus of multiple new players as aging demographics and technology are demanding/creating new possible solutions. Whatever the label e-health, m-health, it is clear that "smart health" solutions will be multi-disciplinary, involving different constituencies with multiple objectives. To engage people and accelerate the diffusion of new ideas there will be a need to incorporate left- and right-brain thinking in balance (high-tech; hightouch). The diffusion of new ideas is greatly enhanced by the almost ubiquitous participation in social. Indeed, narratives and social media are integral parts of today's connected world. Social sharing of new health ideas can create new and improved lifestyle behaviours.

What has remained true around the world during this period of increasing flux is the increasing importance of healthcare, for peoples of the world. Aging demographics and the stress they pose on existing social welfare systems will affect mature and emerging economies, alike. None more so than Japan where its super-aging society is looking for new holistic social solutions that could be the model around the world.

At the same time, governments are encouraging individuals to take more responsibility for their health, and this is creating a mindset shift from healthcare for treatment to a more lifestyle, preventative stance, which further increases interest in the broad area of health and well-being. Wellness is on-trend globally, not simply because of the aging demographics in many mature markets but because of changing attitudes and behaviors of the younger millennials who are looking for "healthier" options, reflective of seeking a healthy and balanced life. Health is no longer about illness; it is about wellness. It is increasingly a daily concern, thinking about diet and activity with a focus on tomorrow and an enduring healthy lifestyle. Our mindset should increasingly realign to think about enhancing "healthspan" rather than a concern with a longer lifespan. "The illiterate of the $21^{\text {st }}$ century will not be those who cannot read and write, but those who cannot learn, unlearn and relearn" (Toffler, 1970).

Technology, in myriads of ways, has the potential to transform to make future healthcare more personal, precise, and preventative. To effect such change and realise smart health expectations of multi-disciplinary, scientific, and medical inventions there will be a necessity for clear, consistent, and coherent communications to multiple constituencies (objectives). In thinking "outside of the box" the imperative is also to act outside of the box and be cognizant of the translational requirements to innovate.

Once upon a time, you could succeed in business by building a better mousetrap-a product that was better than your competitors. Today, you need to build a better platform, ecosystem, or interaction field (Joachimsthaler, 2020), where 
collaboration replaces competition to create shared value. The internet is built of connected minds exhibiting behaviors in response to a stimulus. Every story you can imagine is most likely already there and individuals can find support for their views. Think of the vast array of existing, positive, and negative, stories with in COVID-19 narrative, for example. Social media and social sharing stimulate the imagination, affects attitudes and ultimately behaviour. The diffusion of new ideas, influence, and innovation (Rogers, 1962, 2003) is rapidly accelerated when compared to less than 20 years ago. New ideas and conversations amongst Key Opinion Leaders (KOLs) and communities is greatly enhanced by the almost ubiquitous participation in social media in the mature markets around the world, creating the most efficient and effective distribution system for news and opinion.

To this end, state-of-the-art communication science can ensure the effective and efficiency, and critically empathetic, delivery of the appropriate narratives, in context, to different constituencies. Not every individual will have the same impact on change; some are more important than others to effect change.

As countries try to balance their social health costs, especially in ageing demographies, the increasing need for self-medication necessitates that policy align with the attitudinal shift from a treatment to a prophylactic priority in healthcare. As such, the longstanding World Health Organisation's (WHO, 1948) definition of healthcare:

"Health is a state of complete physical, mental and social well-being and not merely the absence of disease or infirmity"

Is at odds with empowering the individual to make personal and potentially ambiguous choices regarding their own health. Narratives are the opportunity to connect.

While social cost drivers were part of this transformation from healthcare to well-being there was an increasing recognition of the impact and importance of lifestyle-related disease. It is generally accepted that approximately 60 percent of mortality and 80 percent of the global disease burden are a function of just four LifeStyle choices-lack of exercise; poor nutrition; smoking and alcohol abuse. Thus, a new perspective on health insurance could incentivise customers to make healthier and better lifestyle choices. The risk mindset simply needs to change to create such new and personalized solutions facilitated by Big Data and AI. The risk would be assessed less on broad demographic metrics but driven by an individuals' behaviour. A broader and more dynamic view of health needs improved health literacy (Sørensen et al., 2012) so that individuals could make such informed lifestyle choices.

Attitude naturally drives behaviour, and the "Positive Health" (Huber, 2011) initiative offers a coherent framework to effect healthy lifestyle behaviour. Social media, and social sharing of healthy lifestyle can act as both a catalyst for, and an accelerator to, the take-up of new such choices. Understanding what is important to people enables policy makers and educators to engage with communities in a relevant meaningful and effective manner. The narratives that are shaping 
our digital lives can be the basis of behavioural shifts that can enhance people's QOL (Quality of Life). Positive Health offers a potential, patient-centric, framework of health in which social sharing can enhance its take-up and diffusion. Such thinking was a major departure from the WHO's definition of health. Practically, it provides a personal, patient-centric, framework of health (Huber et al., 2016) which is aligning with the media transformations away from mass media where social sharing can enhance the take-up and diffusion of new lifestyle choices.

\subsection{End of the Mass-Age Era}

Prior to the wide availability of the internet communications in the late 1990's, the twentieth century communications were dominated by multiple broadcast mass media channels. Marshall McLuhan's seminal media treatise, The Medium is the Massage (McLuhan \& Foire, 1967), evaluates the top down, western-led broadcast, mass media and its global impact.

While western values were spread around the world by mass media, the internet completely changed that dynamic since it provided open access to a flat network, in which anyone, anywhere, can participate in an apparently fragmented world (Riley, 2017). It may appear messy, but it facilitates direct messaging for everyone, anywhere, anytime to like-minded communities; the MessAge. This dramatic shift in orientation necessitates a deeper understanding of, and willingness to, embrace different cultures (Hofstede, 2001), or not, if one wishes to remain disconnected.

\subsection{A Question of Trust and Democratizing Access in the New Mess-Age Era}

Critically, trust is paramount as it is amplified in a social setting and more than ever people find trusted voices in their networks. COVID-19 has played a central role in disseminating information that led to people to act, often quicker than governments. For some it is viewed as "the internet's first truly great informational triumph" (Gans, 2020).

However, at the same time, with more information, readily available, people do not feel better informed rather there is an increasing concern about what information is correct. Edelman's annual research (Edelman Trust Barometer, 2021) refers to year of the pandemic being characterised by an "epidemic of misinformation... in an environment of information bankruptcy". Trust (will be key to realise the potential, since it is the social bond between individuals, and more than ever people trust people. Naturally, messages have to a personal relevance (often in context), convey a sense of authenticity as well as understanding the current situation so that expectations can be aligned credibly.

\section{Narratives Can Shape Our Lives}

\subsection{Narrative Economics: Stories That Go Viral}

At the outset we should stress that these analyses are not just identifying some 
interesting things but things that are important to people now! So, from a corporate or policy perspective aligning with stories that the people feel are driving their current feelings is important allows one to beyond Thought Leadership pieces to creating strategic leadership narratives than effect change.

People have always been attuned to narratives, factual or not, to validate their behaviour. The work of Nobel laureate Shiller (2019) in Narrative Economics is particularly relevant. "When we are asleep at night," he suggests, "narratives appear to us in the form of dreams. We do not dream of equations or geometric figures without some human element." He has studied the epidemiology of narratives and revealed how when contagious narratives go viral, they can create major economic impact. He has shown how the popular narratives of their times drove the 1920-1921 Depression, the Great Depression of the 1930s, the Recession of 2007-2009 and fuel today's socio-economic-political opinions.

\subsection{Predictive Insight Engine}

The ubiquity of the internet and mobility have enhanced the importance of social media [first coined in 1994 by two of the authors and the founders of Significance Systems, Darrell Berry and John Ricketts (Bercovici, 2010)], and social sharing in effecting change. While witnessing the economic successes from readily scalable platform businesses and digital ecosystems across the world, people have benefited from a new standard of utility in service.

However, traditional consumer/market research is by its' very nature akin to looking in the rear-view mirror while driving. It has leveraged technology to develop faster and cheaper research approaches, obviating the need for a fieldforce of interviewers. One might argue it simply provides similar wrong answers quicker. For example, social listening, provides volumetric measures of comments. Citations of a topic are categorised and counted, then averaged and subtracted for sentiment. However, frequency is not uniformly significant, especially in the digital context where personalization is the key characteristic of engagement. This is analogous to wronging adopting the notion of reach and frequency, popularized for mass-media, to the digital context. In this approach, the signal of "what is important" is not isolated from the noise of "what is not".

While such platforms can provide quick measures of the penetration of topics, they are poor in predicting future behaviour. Berry and Ricketts, founding Significance Systems (2021), wanted something better and developed earth.ai; a platform for strategic understanding and forward-looking decision-making.

Significance System's adopts a different approach by to explicitly extracting insights from on-going global narratives. Their proven and proprietary platform earth.ai (Figure 1), which analyses millions of behavioural interactions with content, to model human interaction, and to provide an objective read on engagement, media power, and the authentic, emotional drivers of (new) behaviour. It can sense and quantify over 400 named emotional states, in response to any story. The process considers all open data online as contending for consideration. 
Full Data Perspective

Real-world online behaviour

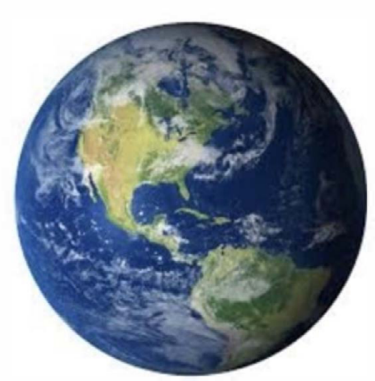

Unique Feature Analysis

See past your media bubble
Narrative \& Decision Science metrics

$\mathrm{L}$ ead indicators

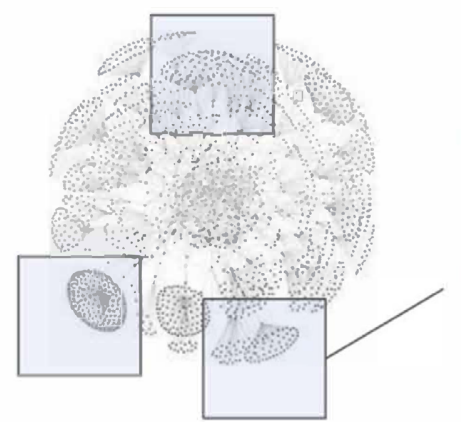

Engagement

Classification

Affect Orientation

Media Power

Content Power

Emotional Response

Topics and Themes

245-dimensions

earth.ai

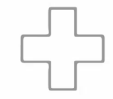

Non-Linear Proprietary

Machine Learning

Figure 1. Significance systems narrative analyses that drive Behaviour. [Significance Systems: "deliver utility from the world's narratives". They leverage their proprietary platform earth.ai, which analyses millions of behavioural interactions with content, to model human interaction, and to provide an objective read on engagement, media power, and the authentic, emotional drivers of (new) behaviour.]

By analogy with the human vision system, in accord with the foundational computational neuroscience Marr (1982, 2010), it pursues a computational-reductionist approach applying multiple layers of processing to identify and extract human-meaningful social-signaling structure within the petabytes of raw topical data available to the first stages of our process. This approach dramatically reduces the volume of data to which they then apply computationally intensive processes such as detailed grammatical analysis. The textual content is interpreted within an affect model.

First, vision would be cleaved into separable "computational theories", in which the visual system is characterized in terms of its computational goals and the strategies by which they are carried out. Each such computational theory could then be investigated in increasingly concrete terms, from symbols and measurements to representations and algorithms, to processes and neural implementations. This paradigm rests on some general expectations of a symbolic information processing system, including Marr's stated principles of explicit naming, modular design, least commitment, and graceful degradation. In retrospect, the computational framework also tacitly rests on additional assumptions about the nature of biological information processing. These include, 1) the separability of computational strategies, 2) the separability of representation, 3) a pipeline nature of information processing, and 4) that the representations employ primitives of low dimensionality.

Moreover, Marr believes that viewing "our brains as information-processing devices is not demeaning and does not negate human values. If anything, it tends to support them and may in the end help us understand what from an informa- 
tion-processing view human values are, why they have selective value, and how they are knitted into the capacity for social mores and organization with which our genes have endowed us" (Marr, 1982, 2010).

As such the understanding of the emotional depth of the narrative, allows for better understanding and connection with people. It is important to be able to understand how the expression changes to remain relevant. Leveraging Big Data and AI to identify specific content (topics, triggers, media channels...) that drive past and future outcomes. The ability, promptly, to go beyond volumetric measure of a topic and understand what is significant, has never been more important to help improve decision-making with a better strategic understanding and ability to connect with your audience.

Recognizing that social sharing is more authentic, and trustable than traditional forms of mass communications it is now possible, with data-based communications insight (Figure 1), to 1) objectively explore these narratives to understand the drivers and dynamics of changing behavior and consensus; 2) probe what people value and feel are more important; and 3) establish how new solutions can be effectively introduced to create new and better behaviours.

\subsection{Narrative Utility}

Measuring and interpreting social and linguistic signals by accessing openly available online content is naturally more directly reflective of human behavior, than traditional qualitative or quantitative survey methodologies. Critically, they also provide a coherent diagnostic base to understand, exploit and change behaviour. Significance Systems measure long-term engagement for narratives. Naturally, a priori distinctive narratives behave in discrete ways and vary in their value and utility. One can classify the utility of different narratives (Table 1). They should be viewed as complex, organic structures, with unique behaviours and characteristics.

Table 1. Narrative categorization.

\begin{tabular}{cl}
\hline Category & \multicolumn{1}{c}{ Characteristics } \\
\hline Timeless & $\begin{array}{l}\text { Long-term, deep engagement with high value, driven by } \\
\text { small number of key players considered experts and } \\
\text { authorities. Part of culture and society and expected to } \\
\text { persist and grow. }\end{array}$ \\
& $\begin{array}{l}\text { Intensely engaged with strong timeless themes. Dynamic, } \\
\text { fast changing with potential to change behavior and } \\
\text { transform the world. } \\
\text { Transformational } \\
\text { Transient }\end{array}$ \\
& $\begin{array}{l}\text { Low consensus and low diversity of points of view and } \\
\text { not expected to persist or grow. White noise. }\end{array}$ \\
& $\begin{array}{l}\text { Intense debate driven by personal experiences or } \\
\text { commercial perspectives bringing divergent point of views } \\
\text { Tribal }\end{array}$ \\
& and hence no impact. Noise. \\
\hline
\end{tabular}


Most narratives are Transient (82\%). Such narratives will fall away without significant investment. These are poor choices for communications, since as issues, they are not expected to persist or grow. Strategically, such narratives are often easy to "own", but they must be driven, or connected to greater relevance and/or differentiation, to have any long-term value. Tribal (11\%) narratives are characterised by intense debate, being driven by personal experiences or commercial perspectives, bringing divergent POVs. Most of this debate, therefore, has no impact. Although it is easy to be a participant, it is far more difficult to be a player or leader in such narratives. Those narratives that have the greatest potential utility are Transformational and Timeless. Transformational (2\%) narratives are characterised by intensely, engaged experiences with strong timeless themes. These narratives are fast-changing, yet potentially result in lasting transformation of the world. Timeless (5\%) narratives are expected to persist or grow. They are characterised by long-term, deep engagement. These narratives are good choices for communication activities. If one considers the narratives of the top 100 brands/companies then their effective communications strategies are focused. One sees Timeless engagement representing at least 90 percent of the narratives (Significance Systems).

Timeless and Transformational narratives are those that can effect change, implement policy, and create sustainable value. Significantly, this allows one to identify, at any time, what is important to people, so that one can readily participate with topical conversations in a relevant and credible manner; to "engage with engagement". It is more effective and efficient to be part of the on-going story rather than to try to intrude from outside, which has historically been the traditional mass communication norm. Since it is people who trust people, this type of analysis enables one to "engage with engagement" and thus be part of the on-going story rather than to try to dominate it from outside, which has been the traditional mass communication norm of intrusion. The methodology is breaking the mold of traditional consumer research methodologies providing more relevant, timely and actionable insights.

In tracking narratives that can shape our world, we recognize explicitly that:

$\checkmark$ Popular stories affect individual and community behavior.

$\checkmark$ Improve decision-making comes by knowing and addressing what people themselves feel is important.

$\checkmark$ Relevant and timely communications, in context, can stimulate change in perception and behaviour.

$\checkmark$ Not just content but tone is important [has been exemplified by changing affect during COVID-19 (Figure 2)].

To leverage the strong story, it is now possible to go beyond traditional media planning considerations and focus on the strong narrative (Table 2). Simply:

$\checkmark$ Know what to say.

$\checkmark$ How to say it.

$\checkmark$ Who to say it to.

$\checkmark$ Where to say it. 


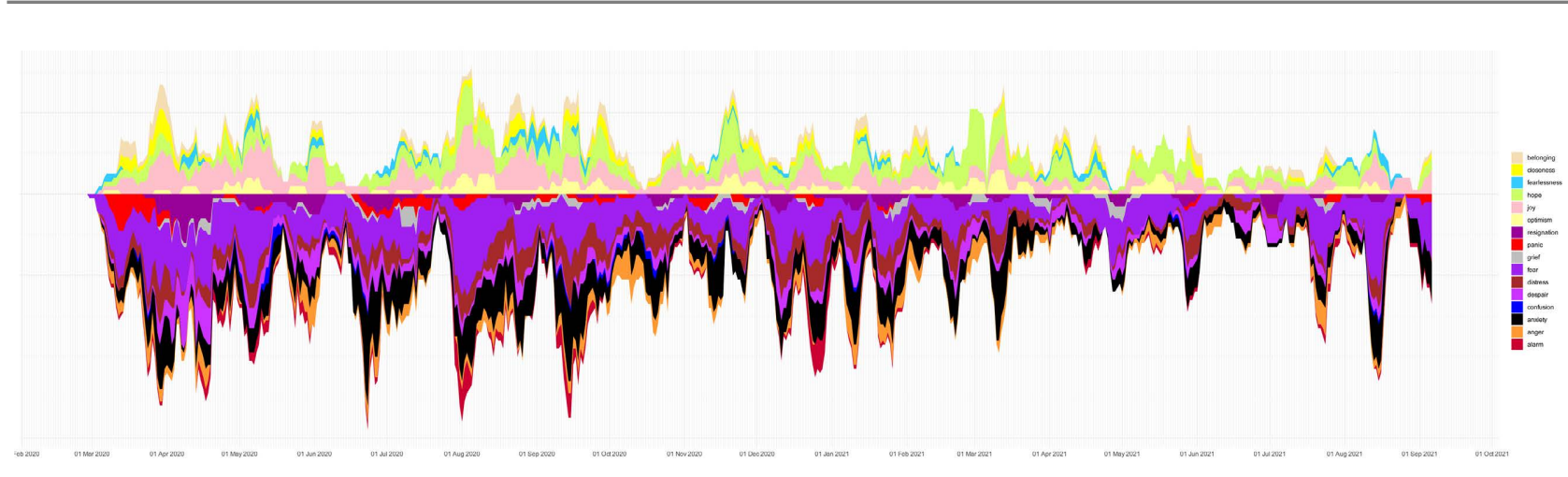

Figure 2. UK; Affect in Covid-19 narrative (March 2020-Sept $6^{\text {th }}, 2021$ ).

Table 2. User experience.

\begin{tabular}{ll}
\hline \multicolumn{1}{c}{ Output } & \multicolumn{1}{c}{ Characteristics } \\
\hline 1: Engagement Classification & $\begin{array}{l}\text { to assess where opportunities exist to annex } \\
\text { Timeless and Transformative narratives } \\
\text { 2: Affect Orientation }\end{array}$ \\
to understand the emotional response of the narrative \\
identify and rank media by their power to influence \\
4: Content Power & $\begin{array}{l}\text { assess the power of individual pieces of content } \\
\text { understand how the market feel/emotional tone of } \\
\text { the significant content } \\
\text { confirm and leverage the interconnectivity of topics } \\
\text { and emergent themes to enhance relevance and } \\
\text { credibility }\end{array}$ \\
\hline
\end{tabular}

\subsection{Lifestyle by Design}

A core tenet of The University of Tokyo's LifeStyle by Design research initiative is the increasing need to empower the individual to make an informed choice about their own healthy life options, to improve their life satisfaction (Clark et al., 2018; Layard, 2020). As noted above, to execute this policy demands greater health literacy amongst the population. As self-medication and healthy lifestyle choices become increasingly important social sharing of new ideas and practices can spread new ideas, that change attitudes and create new everyday behaviours. This will have the potential to enhance "healthspan" (Peterson, 2017); the length of time people are healthy, rather than longevity.

Human choice is a basic freedom and philosophically can have several dimensions including ethical considerations. Specifically, LifeStyle by Design promotes and delivers healthier lifestyle bringing a new balance to the physical, nutritional and social needs to bring an individual's balance to enhance their QOL. It is widely accepted that roughly 60 percent of mortality and 80 percent of the global disease burden are a function of just four lifestyle choices-lack of exercise; poor nutrition; smoking and alcohol abuse. People who stay active tend to be happier, but too much exercise can be detrimental to your mental health. Design Thinkers are leaders who the skills of a designer with conventional corporate strategy 
to drive the open and unashamed innovation that revolutionizes everything from products to processes (Clark \& Yamazaki, 2020).

Design Thinking the process essentially condenses to a concentration on experiential (sensory), emotional and integral (cross-sector) intelligence. Thus, in a period of renewal, the character of any LifeStyle by Design would need to be:

- Progressive (a questioning disruptive innovator);

- Collaborative (brings multidisciplinary skills and melds a team to holistically explore "what can be");

- Authoritative (focused with access to execute material change).

Moreover, as change is unpredictable, then leadership characteristics must be radically different and dynamic with an ability to encourage experimentation and willingness to adapt. With the stated increasing importance of social sharing, it becomes an imperative to be able to craft and execute the strategic leadership narratives.

LifeStyle by Design supports scientific and social research, education, new partnerships, and deregulation to accelerate the adoption of innovative solutions focused on holistic well-being for the individual and community to enhance QOL. Since the scope of potential collaborators is broad it is imperative to establish early on a construct that helps focus the design thinkers and ensure all the necessary competencies are brought to bear to develop new solutions; to move with convergent and divergent thinking and assess new alternate outcome states to move from "what is" to "what can be". Going forward the personal and proactive changes now needed can lead to tangible improvements in Life Satisfaction/QOL, but it demands improved clarity and depth of communications to empower individuals to take more personal responsibility; to make informed choices. Without the communication system, in extreme, any invention will remain in a vacuum and have no in market impact that an innovation, by its nature, demands.

\subsection{Virtual Living Lab}

LifeStyle by Design proposes to leverage social media to ensure the effective and efficient delivery of the appropriate narratives, in context, to different constituencies. It is anticipated that this will help create community capital (Parsfield et al. Eds., 2015). We began in mid-2019 to benchmark twenty key narratives (Table 3 ) in the UK and Japan, to draw scalable communication implications for policymakers and public and private institutions, alike. The original premise was to understand what people wanted and that would enable innovation to magnify and annex on-going trends. Beyond creating a benchmark of attitudes and behavior, to monitor the mood of society, it was also intended to be comparative in nature focusing on both Japan and the UK, to help affect policy or monitor any subsequent action plan. As Geert Hofstede's (2001) seminal work, which made him the most-cited European social scientist, demonstrated at the early stages of globalization; "National Culture cannot be changed, but you should understand and respect it." Naturally one can hypothesise material differences in the nature 
Table 3. Lifestyle Narratives tracked in the UK and Japan.

\begin{tabular}{|c|c|}
\hline English & Japanese \\
\hline well-being & ウェルビーイング \\
\hline wellness & 健康 \\
\hline personal happiness & 個人的な幸せ \\
\hline personal satisfaction & 個人的な満足 \\
\hline leisure time & 余暇 \\
\hline personal employment & 個人雇用 \\
\hline personal life balance & 私生活バランス \\
\hline personal friendship & 個人的な友情 \\
\hline my family & 私の家族 \\
\hline personal nutrition balance & 個人の栄養バランス \\
\hline personal activity & 個人的な活動 \\
\hline my free time & 私の自由な時間 \\
\hline motivation & 動機 \\
\hline my community & 私のコミュニティ \\
\hline personal bonding & 個人的な絆 \\
\hline being employed & 雇用されている \\
\hline personal wealth & 個人の富 \\
\hline personal relationships & 個人的な関係 \\
\hline my resilience & 私の回復力 \\
\hline personal confidence & 個人的な自信 \\
\hline personal optimism & 個人楽観主義 \\
\hline personal pessimism & 個人的な悲観主義 \\
\hline social stability & 社会的安定 \\
\hline economic growth & 経済成長 \\
\hline
\end{tabular}

of the narratives associated with LifeStyle health choices and self-medication due to differences in primary healthcare provision between the two countries. For example, the primacy of the General Practitioner as the interface for the patient/family in the UK (Pike et al., 1981).

The benchmark primary research began in June 2019, with a first wave of the LifeStyle by Design narratives in Japan and the UK; followed by a second wave in December 2019; with a special third wave, April 2020, when the UK was in lockdown and Japan had the national emergency in place. Subsequent waves included in this paper were in June and December 2020, as well as June 2021. To analyse the narratives (as in all the Figures in this paper), in each research wave, we look at all online sources, in Japan and the UK respectively, up to the date of 
the wave. There is no time window. So, depending on the specific narrative, which self organises, it could be dominated by recent content... or not. This is the basis of what is referred to as the LifeStyle by Design, Virtual, Living Lab (Beaumont \& Ricketts, 2020).

The first two waves of research to benchmark the basic structure of the narratives was undertaken in 2019. Then in early 2020, a global pandemic hit that quickly became a significant moment in history (Beaumont \& Ricketts, 2020). COVID-19 will go down as a rare event in human history, first an unprecedented human tragedy. It has completely disrupted the status quo, changing everyone's daily lives, heightening uncertainty, so that no one can take even the little things in life for granted. Our tracking of lifestyle narratives became more important, a Virtual Living Lab. It uniquely helps to understand what is significant to people in real-time; both the content and the tone-not what commentators, companies, or politicians think is important. Very often there can be a disconnect between what stakeholder's think is important and what is important since it is natural for people to influenced by their own media bubbles.

That said, social and political commentators are referring to the tectonic shift created by the pandemic in terms of different eras BC, DC, and AC [Before, During and After COVID-19, (Nelms, 2020)]. Crisis management and risk communications have come to the fore with the onset of the global COVID-19 pandemic, which is creating unprecedented social, economic, and political challenges as peoples around the world are having to change their lifestyles.

To "engage with engagement" it is not simply having the appropriate content, but it is also critical to convey the appropriate tone. This is dramatically illustrated by the emotional dynamics at a time of perceived vulnerability/uncertainty during 2020 global pandemic, when it is evident that, with conflicting policy options, unclear and sometimes contradictory messages only exacerbated the difficult situation. Figure 2 shows the affect associated with COVID-19 from March 2020 when the country went into the first lockdown through Sept $6^{\text {th }}, 2021$. It starts to track the affective response to COVID-19 from the March $1^{\text {st }}$; the date the UK Health Secretary set out the COVID-19 "battle plan". Above the vertical in Figure 2, we have the positive affective response of belonging, optimism, fearlessness, joy, and hope. Their peaks and throughs at times naturally inversely correspond with the negative responses shown below the vertical. The two national lockdowns broadly reduced fear and despair, and to a lesser extent the sense of resignation. That said, anxiety was heightened in late June ( $3^{\text {rd }}$ easing of lockdown restrictions), early August 2020 (delay of reopening establishments), and mid-September ("Rule of six" introduced) in part reflecting less panic and fear.

Explicitly considering the affective response one might hypothesise enhance policy decisions, communications approaches, and understanding of the healthcare responses and improve the confidence of the nation. This would obviate the feelings of confusion indicated in blue (Figure 2) when different policy voices were, for example, suggesting localized responses; varying and quickly changing 
rules associated with foreign travel, as well as the conflict created by about turns regarding examination results and University terms starting and students in campus lockdown. In August 2021 with the end of the lockdown there is some joy, hope and fearlessness, but that is dominated by fear and anxiety which has replaced the anger felt over uncertainty earlier in the summer.

Affect is a rich measure of the emotional tone of the narrative. It is felt emotion which is a powerful descriptor of future behaviour. Below the horizontal we see negative emotions dominating the positive senses (above the vertical). Initial panic (red) was replaced by fear, grief, despair and resignation, and material periods of confusion and anger. People's resilience (above the vertical) came through with a greater sense of belonging helping to maintain hope and create optimism.

\section{BC and DC Narrative Tracking in Japan and the UK (June 2019-June 2021)}

At the beginning, in June 2019, the encouraging first observation is that many timeless narratives have been identified (Figure 3). They are currently ill-defined but has issues, these narratives are expected to persist or grow. Only 私の回復 力 (My Resilience) is currently transformational. Yet, it is still relatively diffuse, and the existing content does not provide a clear definition (Figure 4). The timeless Japanese narratives (Figure 5) are weaker than those in the UK on average. My Resilience is an open narrative-here's the opportunity to blow it up and own it. Those at the bottom of the UK are narratives (wording) that have not yet been captured. The timeless narratives that are towards the top are generally about "My..." perhaps an indication of relatively greater individuality (than found in Japan)? That there are no transformational narratives in the UK analyses might be because they have moved to become Timeless as they started rather earlier. Benchmarking these narratives, over time, may well reflect both differences in LifeStyle by Design take-up, but also cultural nuances.

In Japan, all the lifestyle narratives are currently poorly defined (Figure 4), but eleven of the narratives are timeless and one is transformational (Figure 5). Therein lies an opportunity. Content efficiency is a measure of the extent to which the existing narrative content is significant. High content efficiency means that much existing content is significant, whereas a low score means there is a gap between the needs of the narrative, and the currently created content.

In Japan, eleven of the narratives are timeless and 1 is transformational (Figure 5); but all are currently poorly defined (Figure 4) and therein lies an opportunity. Content efficiency is a measure of the extent to which the existing narrative content is significant. High content efficiency means that much existing content is significant, whereas a low score means there is a gap between the needs of the narrative, and the currently created content.

This can be illustrated by taking a deeper dive into any one of the Timeless narratives. “ウェルビーイング: Well-Being” is highly engaging but poorly 


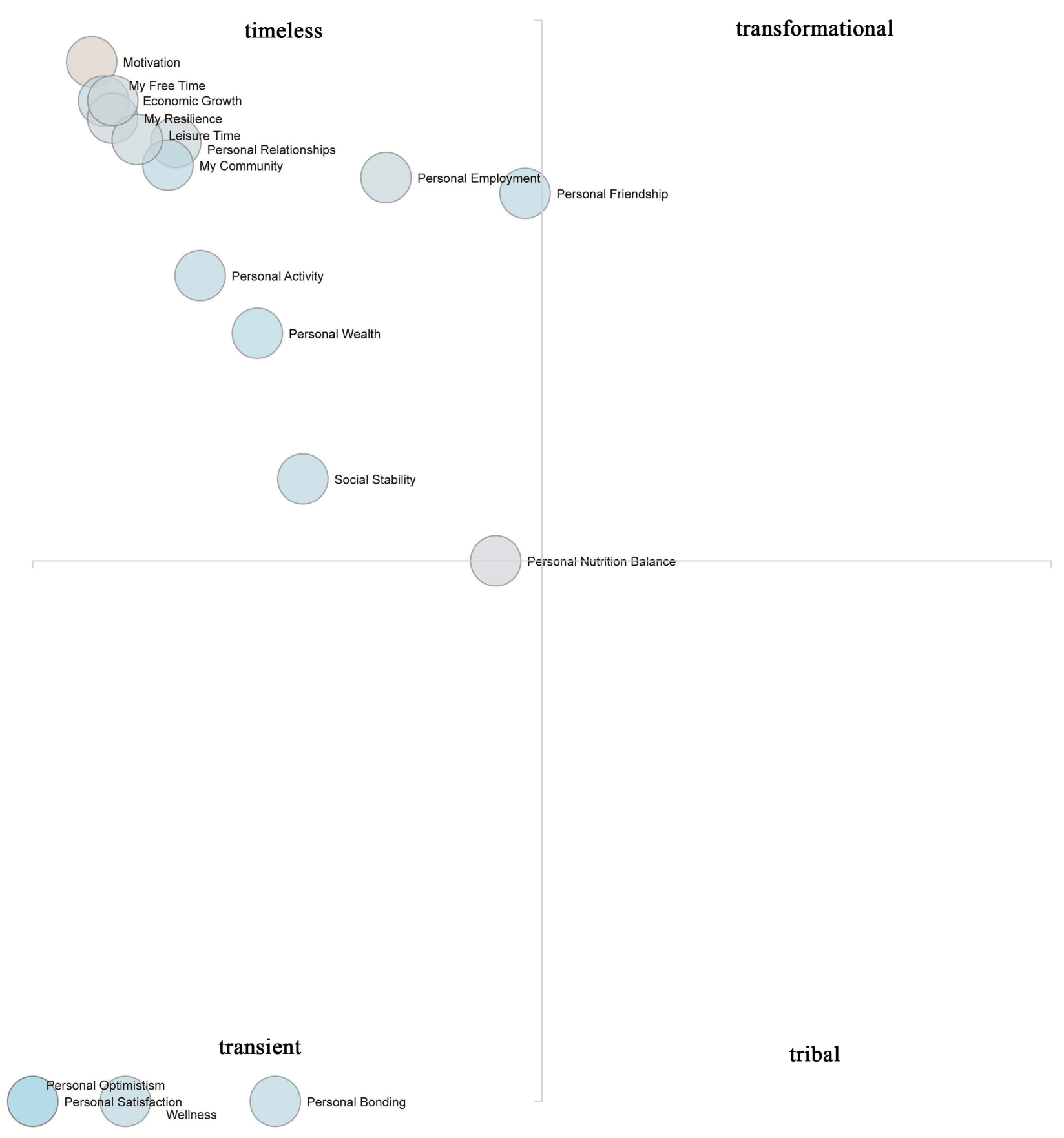

Figure 3. UK narrative landscape June 2019.

\section{Content Efficiency}

Weak

Average

Strong

Figure 4. Narrative content power.

served by current content. Its' affect orientation is very positive being powered by enthusiasm and energy, that could enhance growth and adaptation, and thus drive behaviour. 


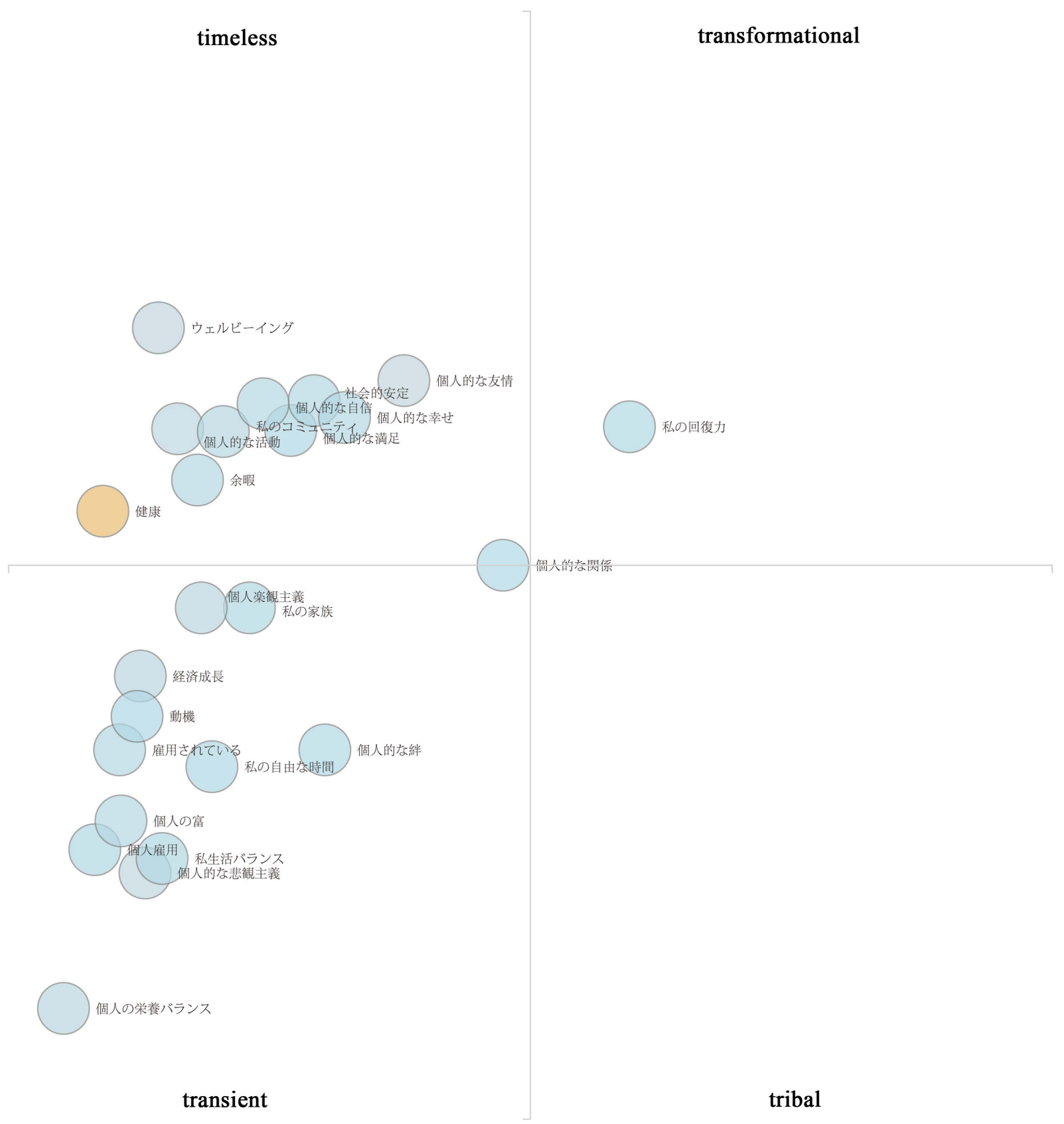

Figure 5. Japan narrative landscape June 2019.

By December 2020 (Figure 6 \& Figure 7) when the COVID-19 pandemic has been directly and fundamentally transforming people's lives, almost constantly, and yet there was no respite available and vaccinations were only being discussed several the narratives, especially those that are more about personal perspectives and control have had their foundations removed and consequently they have taken on characteristics of a transient nature. Wellness, resilience, and a sense of community with strength from family and local friends providing personal confidence and motivating a sense of shared stability rather than relying on a societal foundation. 


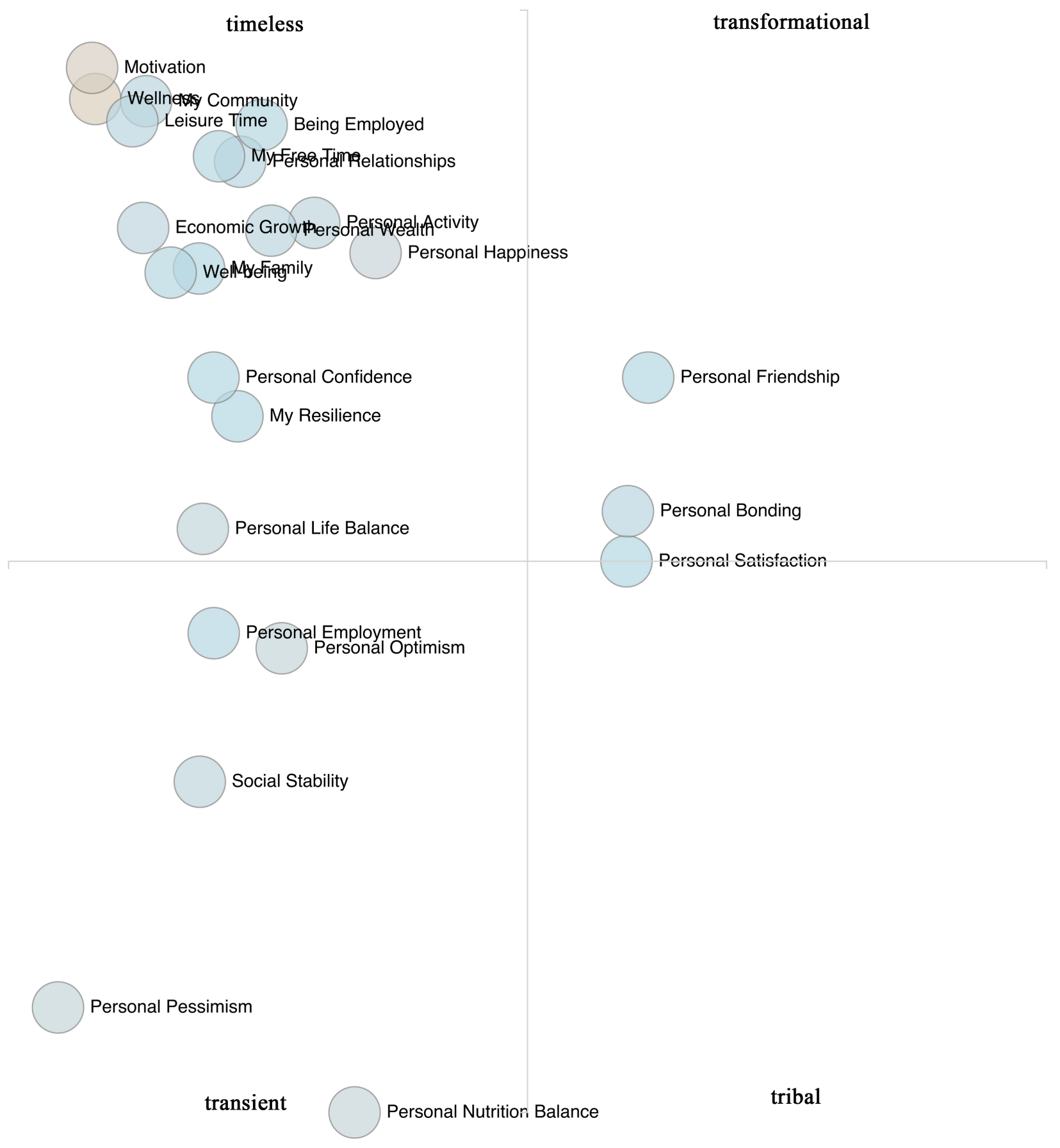

Figure 6. UK narrative landscape December 2020.

With the second analysis of the narratives In December 2019, the basis for benchmarking proactive activity had been established. That said, it was inappropriate with only two data points to focus on apparent dynamics since overall engagement was essentially unchanged in each market. So, while there is no evidence of seasonality amongst the narratives, at present there is higher average engagement for the narratives in the UK. That may well be a natural consequence of culture which other researchers have indicated has been telling in the 


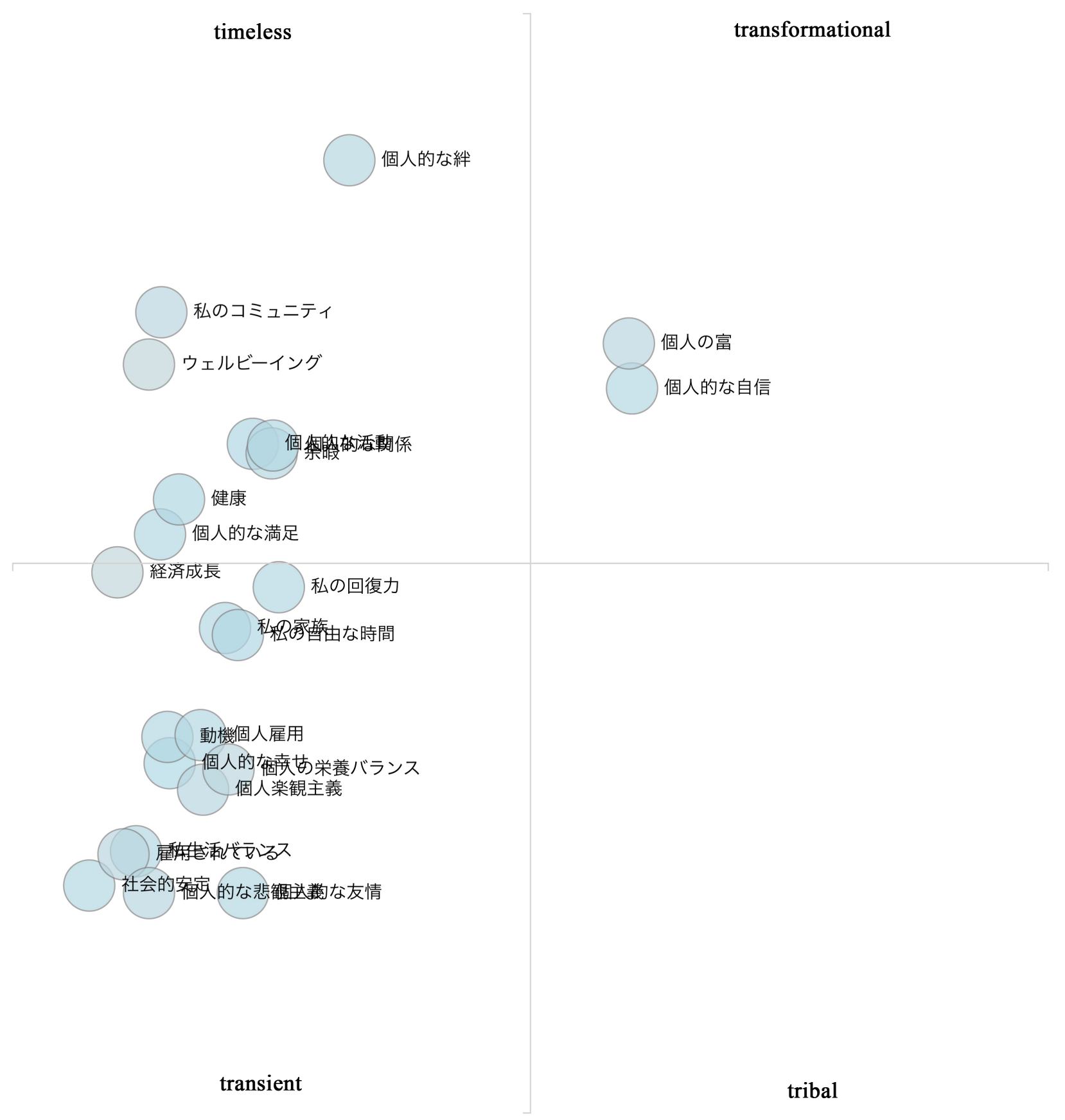

Figure 7. Japan narrative landscape December 2020.

different, but non-random, responses to the pandemic by different countries (Gelfand et al., 2021; FT, 2021). What is evident in the UK (Figure 2) is that the pandemic presented a rollercoaster of emotions as numerous policy changes and a lack of empathy heightened fear and mistrust. In part because of contradictory statements by different levels of the public sector and a seemingly myriad of, and regularity to regulatory changes (The Guardian, 2021). That said, there is some evidence that the UK market is behaving differently after the Brexit election. For example, the social stability narrative appears to have been soothed by the clarity 
of the clear UK election results, of early December 2019.

Those narratives that have the greatest potential utility are timeless and transformational.

\subsection{Transformational Narratives}

Transformational (2\%) narratives are characterised by intensely, engaged experiences with strong timeless themes. These narratives are fast-changing yet can potentially result in a lasting transformation of the world. During the pandemic not surprisingly some of the narratives themselves became transformational as they reflected a narrowcast of heightened interest in a particular story.

In December 2020, in Japan (Figure 7) it was personal wealth (個人の富) and personal confidence (個人的な自信) (Table 4). While for both the content efficiency was weak, the affect orientation was active and positive reflective of the dynamism of the moment. The orientation of the story was for personal wealth was very immediate with key topics being the short-term concerned with advances that might help with shopping, budgeting, and feeding the family. In mid-2020, after the first national emergency the Japanese government made a one-time, Yen 100,000 cash payment to every resident of Japan. This uniform payment did not obviate severe financial difficulties for low-income families, and stress for near- and long-term became evident.

Regarding personal confidence, this showed a different reaction between men and women, but for both their confidence was weakened. For the former the focus was on their job, and for some households the question of taking on a second job. With more WFH (video) becoming more prevalent, for men confidence put into focus their consideration of "beauty" facial products. It was noteworthy that Shiseido (March 2021) introduced an AR filter from Shiseido Men to try men's make-up at online meetings. A smart marketing innovation

Table 4. Transformational lifestyle narratives in the UK and Japan (June 2019-June 2021).

\begin{tabular}{ccc}
\hline Transformational & & \\
\hline Wave & Japan & UK \\
\hline 19-Jun & My Resilience & Personal Wealth, \\
19-Dec & Personal Friendship & Personal Satisfaction \\
20-Apr & $\begin{array}{c}\text { Personal Friendship } \\
\text { (\& Timeless) }\end{array}$ & Personal Friendship \\
20-Jun & $\begin{array}{c}\text { Personal Friendship, } \\
\text { Personal Bonding }\end{array}$ & Being Employed (\&Timeless) \\
& $\begin{array}{c}\text { Personal Confidence, } \\
\text { Personal Wealth }\end{array}$ & $\begin{array}{c}\text { Personal Friendship, Personal } \\
\text { Bonding, Personal Satisfaction }\end{array}$ \\
21-Jun & & \\
\hline
\end{tabular}


since it engaged with an audience that they had traditionally not, on mass, and who would not wish to go to the traditional retail environment. With e-commerce burgeoning male grooming growth trajectory magnified significantly.

A hidden consequence of falling confidence was the increase in mental health (Sakamoto et al., 2021), when 2020 saw for the first time in a decade a rise in the number of suicides in Japan, to 20,919. In fact, more people died from suicide in October 2020, than from COVID-19 in all of 2020. Of notable concern, against a backcloth of relatively poor diversity governance, women have been impacted most. The increase was especially pronounced among women younger than 30 , potentially due to the COVID-19 pandemic's disproportionate effect on part-time and travel industry employees.

\subsection{Timeless Narratives}

Timeless (5\%) narratives (Table 5) are expected to persist or grow. They are characterised by long-term, deep engagement. These narratives are good choices for communication activities. If one considers the narratives of the top 100 brands/corporations, then their effective communications strategies are narrowcast, with focused messaging. One sees Timeless engagement representing at least 90 percent of the narratives (Beaumont \& Ricketts, 2020). In the same vein our Lifestyle narratives (Table 3) while being broad in their scope were viewed as topical, after secondary Pre-search, so it was pleasing to find our hypotheses supported by the fact that so many of the narratives were timeless (Table 5).

\section{3. $\mathrm{BC}$ and $\mathrm{DC}$}

For practical convenience to illustrate the nature and scope of how this holistic approach empowers "engaging with engagement" this paper will now focus on Wellness. In all waves of research except June 2019 in the UK (Figure 8), Wellness has been a timeless narrative in both countries. On all occasions its affect orientation was active and positive (Figure 9 for the UK; in June 2019). Since most narratives are neutral this is indicative of Wellness having enthusiasm and energy, with the potential for growth and adaptation, and ability to drive behaviour. The uncertainty and dynamic nature of the situation is exemplified by the timeline of the UK government coronavirus lockdown, March 2020 to June 2021 (IfG, 2021).

In June 2019 when Wellness was a transient narrative in the UK, there was minimal emotional connection (Figure 10), and content focused on history and corporate institutional stances, somewhat distant from individuals.

In the emotional/affect response diagram (Figure 10), positive emotions are highlighted in green, whereas negative emotions are red. If there is a clear tonality to the emotions expressed, such as expectation or apprehension, these are shown in blue/purple. The intensity of the colour indicates the intensity of each emotion. The width of each arc reflects the degree to which the named emotion contributes to the overall emotional response. Broad emotions, such as joy, fear, 


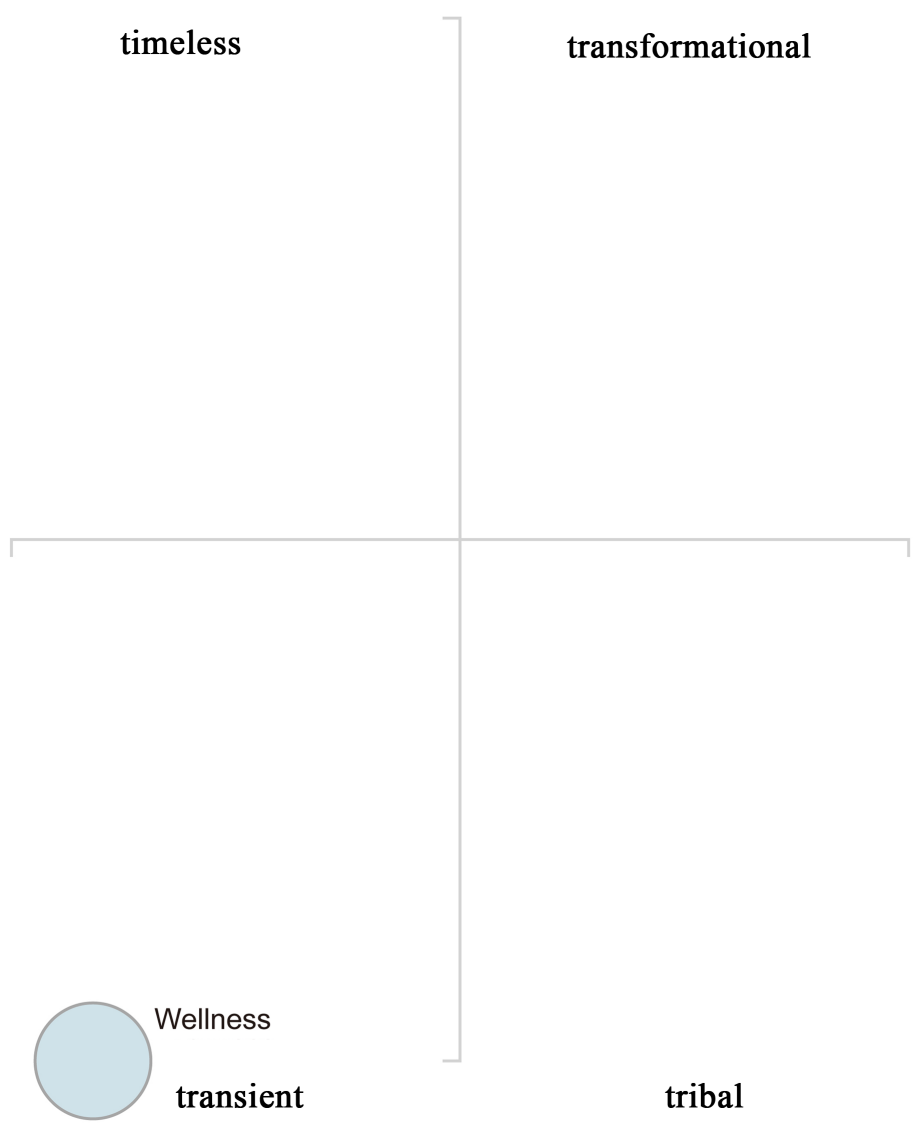

Figure 8. Wellness UK: Narrative categorization June 2019.

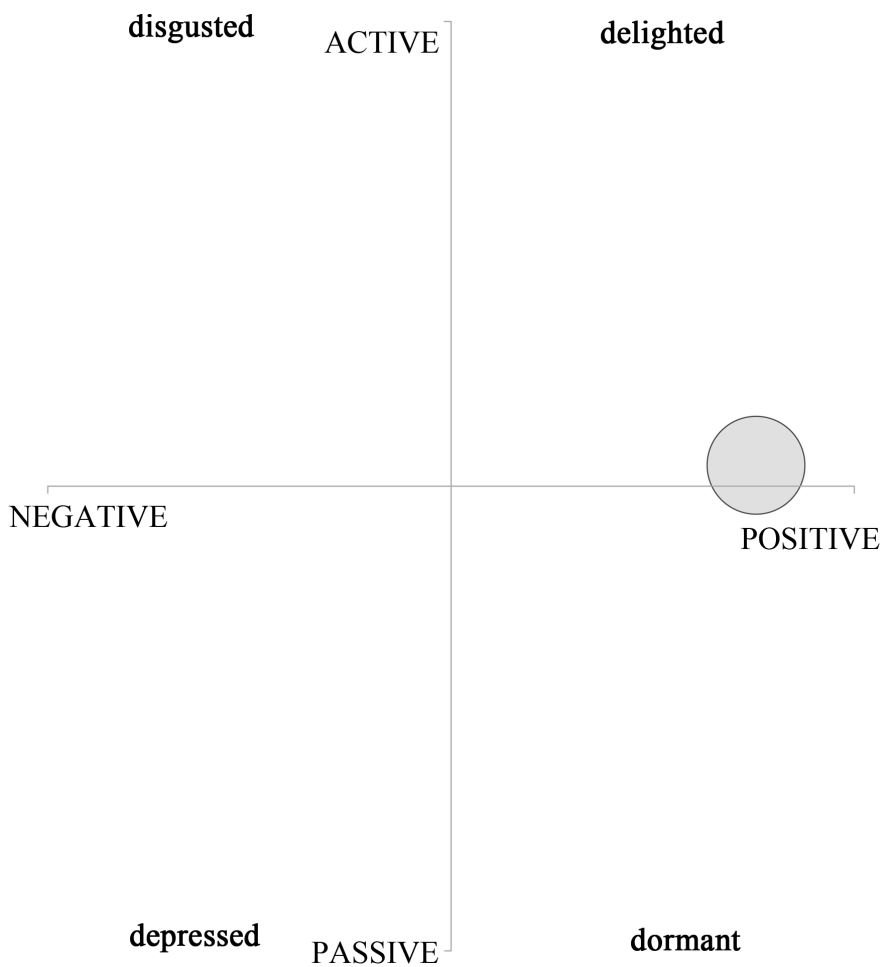

Figure 9. Wellness UK: Narrative orientation June 2019. 
Table 5. Timeless narratives in the UK and Japan (June 2019-June 2021).

\begin{tabular}{|c|c|c|}
\hline \multicolumn{3}{|l|}{ Timeless } \\
\hline Wave & Japan & UK \\
\hline 19-Jun & $\begin{array}{l}\text { Well-Being, Leisure Time, } \\
\text { Personal Friendship, } \\
\text { Personal Happiness, } \\
\text { Personal Activities, } \\
\text { Personal Satisfaction, } \\
\text { Personal Confidence, } \\
\text { Personal Confidence, } \\
\text { Wellness, Social Stability, } \\
\text { My Community }\end{array}$ & $\begin{array}{l}\text { Being Employed, Economic Growth, } \\
\text { Leisure Time, Motivation, } \\
\text { My Community, My Family, } \\
\text { My Free Time, My Resilience, } \\
\text { Personal activity, Personal Confidence, } \\
\text { Personal Employment, } \\
\text { Personal Friendship, } \\
\text { Personal Happiness, } \\
\text { Personal Life Balance, } \\
\text { Personal Relationships, } \\
\text { Personal Wealth, } \\
\text { Social Stability, Well-Being }\end{array}$ \\
\hline 19-Dec & $\begin{array}{l}\text { My Community, Personal } \\
\text { Satisfaction, Wellness, My } \\
\text { Family, Personal Activity, } \\
\text { Social Stability, Leisure Time, } \\
\text { Well-Being, Personal } \\
\text { Happiness, Personal } \\
\text { Relationships }\end{array}$ & $\begin{array}{l}\text { Motivation, Wellness, My Community, } \\
\text { Leisure Time, Personal Relationships } \\
\text { Being Employed, Social Stability, } \\
\text { Economic Growth, Well-being, } \\
\text { Personal Activity, My Resilience, } \\
\text { My Family, Personal Confidence, } \\
\text { FreeTime, Personal Happiness }\end{array}$ \\
\hline 20-Apr & $\begin{array}{l}\text { Well-Being, Personal } \\
\text { Satisfaction, Leisure Time, } \\
\text { Personal Activities, } \\
\text { Personal Confidence, } \\
\text { Personal Relationships, } \\
\text { Wellness, Personal } \\
\text { Happiness, Being Employed, } \\
\text { Personal friendship, } \\
\text { My Family, Social Stability }\end{array}$ & $\begin{array}{l}\text { Motivation, Wellness, Personal } \\
\text { Employment, My Free Time, Leisure Time, } \\
\text { Personal Relationships, My Community, } \\
\text { My Family, Being Employed, } \\
\text { My Resilience, Personal Wealth, } \\
\text { Economic Growth, Personal Confidence, } \\
\text { Personal Activity, Well-Being, } \\
\text { Personal Happiness, Social Stability, } \\
\text { Personal Optimism }\end{array}$ \\
\hline 20-Jun & $\begin{array}{l}\text { My Family, Personal } \\
\text { Relationships, } \\
\text { My Free Time, Wellness, } \\
\text { Well-Being, Leisure Time, } \\
\text { My Community }\end{array}$ & $\begin{array}{l}\text { Motivation, My Free Time, Wellness, } \\
\text { My Resilience, My Community, } \\
\text { Leisure Time, Personal Employment, } \\
\text { Being Employed, Well-Being, My Family, } \\
\text { Economic Growth, Personal Confidence, } \\
\text { Personal Happiness, Personal Wealth, } \\
\text { Personal Activity, } \\
\text { Personal Relationships, } \\
\text { Personal Satisfaction }\end{array}$ \\
\hline 20-Dec & $\begin{array}{l}\text { Personal Bonding, } \\
\text { My Community, Well-Being, } \\
\text { Personal Activity, } \\
\text { Personal Relationships, } \\
\text { Leisure Time, Personal } \\
\text { Satisfaction, Wellness }\end{array}$ & $\begin{array}{l}\text { Motivation, Wellness, My Community, } \\
\text { Leisure Time, Being Employed, } \\
\text { My Free Time, Personal Relationships, } \\
\text { Economic Growth, Personal Activity, } \\
\text { Personal Wealth, My Family, } \\
\text { Well-Being, Personal Happiness, } \\
\text { Personal Confidence, My Resilience, } \\
\text { Personal Life Balance }\end{array}$ \\
\hline
\end{tabular}




\section{Continued}

\begin{tabular}{|c|c|c|}
\hline 21-Jun & $\begin{array}{l}\text { Economic Growth, } \\
\text { Well-Being, } \\
\text { Personal Satisfaction, } \\
\text { Motivation, Wellness, } \\
\text { Leisure Time, } \\
\text { My Community, } \\
\text { Being Employed }\end{array}$ & $\begin{array}{l}\text { Motivation, Wellness, My Community, } \\
\text { My Resilience, My Free Time, } \\
\text { Personal Relationships, Personal Wealth, } \\
\text { Leisure Time, My Free Time, } \\
\text { Personal Relationships, } \\
\text { Economic Growth, Well-Being, } \\
\text { Being Employed, My Family, } \\
\text { Personal Happiness, Personal Confidence, } \\
\text { Personal Activity, Personal Friendship, } \\
\text { Personal Employment }\end{array}$ \\
\hline
\end{tabular}

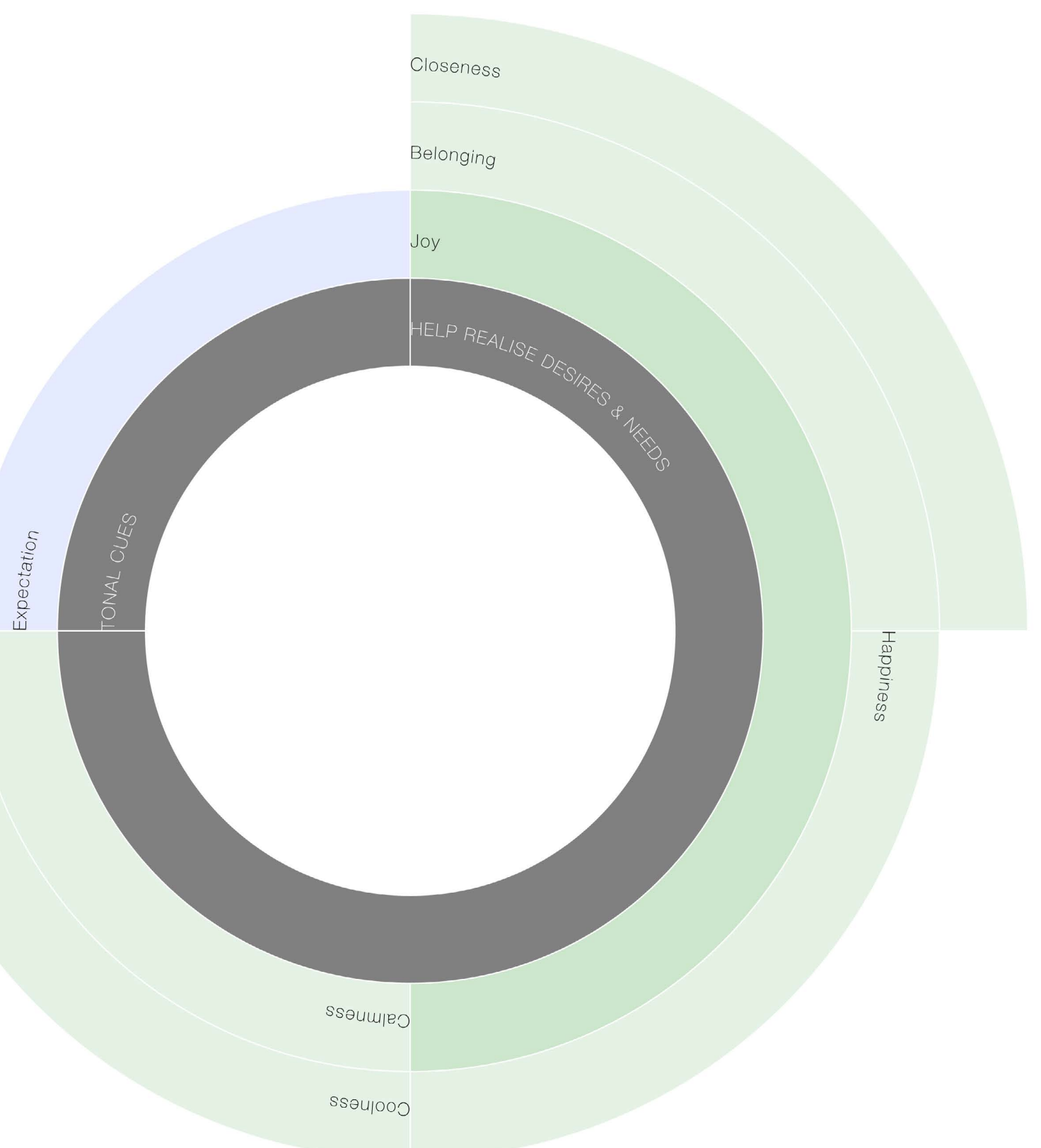

Figure 10. Wellness UK: Affect June 2019. 
and love, are closer to the centre of the chart. The more subtle emotions, which promote those broad emotions, are shown in the concentric rings further out from the centre; cf. in Figure 10, closeness helps promote a sense of belonging and that creates joy. Each ring shows a further level of detail. It is usual for these more subtle emotions to have a larger cognitive component.

In the UK, the Wellness affect orientation is positive (Figure 11) despite being characterized as being a transient narrative in June 2019 (Figure 3). In contrast, Wellness in Japan is timeless (Figure 5, Figure 7 \& Figure 12) and is the narrative amongst those in Japan, at that time, with the highest content efficiency. Most of the associated emotions were positive (Figure 13) but some fear and anxiety was identifiable. Healthy lifestyle activities for some can create a sense a sense of competition, and greater participation can itself have an adverse effect. Not only does the platform provide media power it identifies and ranks the content that is influential, as illustrated in Figure 14.

Content power is a measure of the power of individual pieces of content, to capture and to drive engagement with a narrative's core themes. This measure is independent of volume. At the time, in Japan, Wellness stimulates long-term

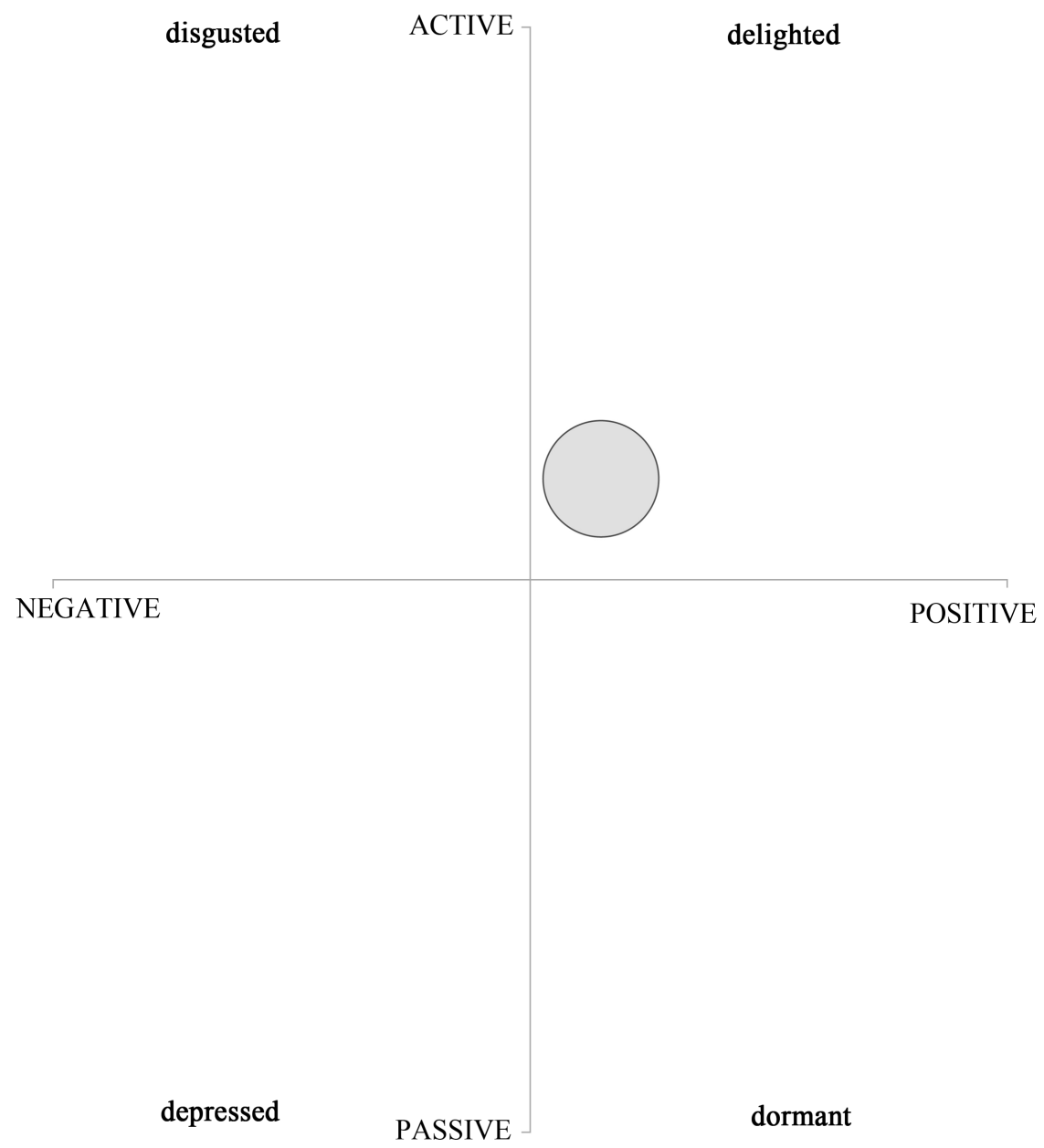

Figure 11. Wellness Japan: Narrative orientation June 2019. 


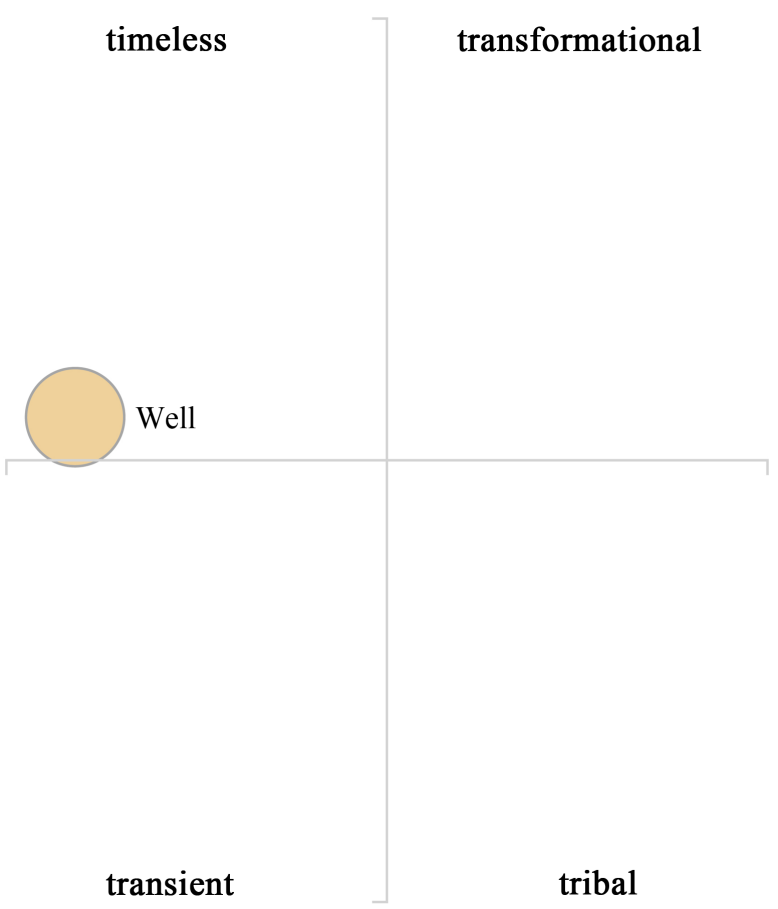

Figure 12. Wellness Japan: Narrative categorization June 2019.

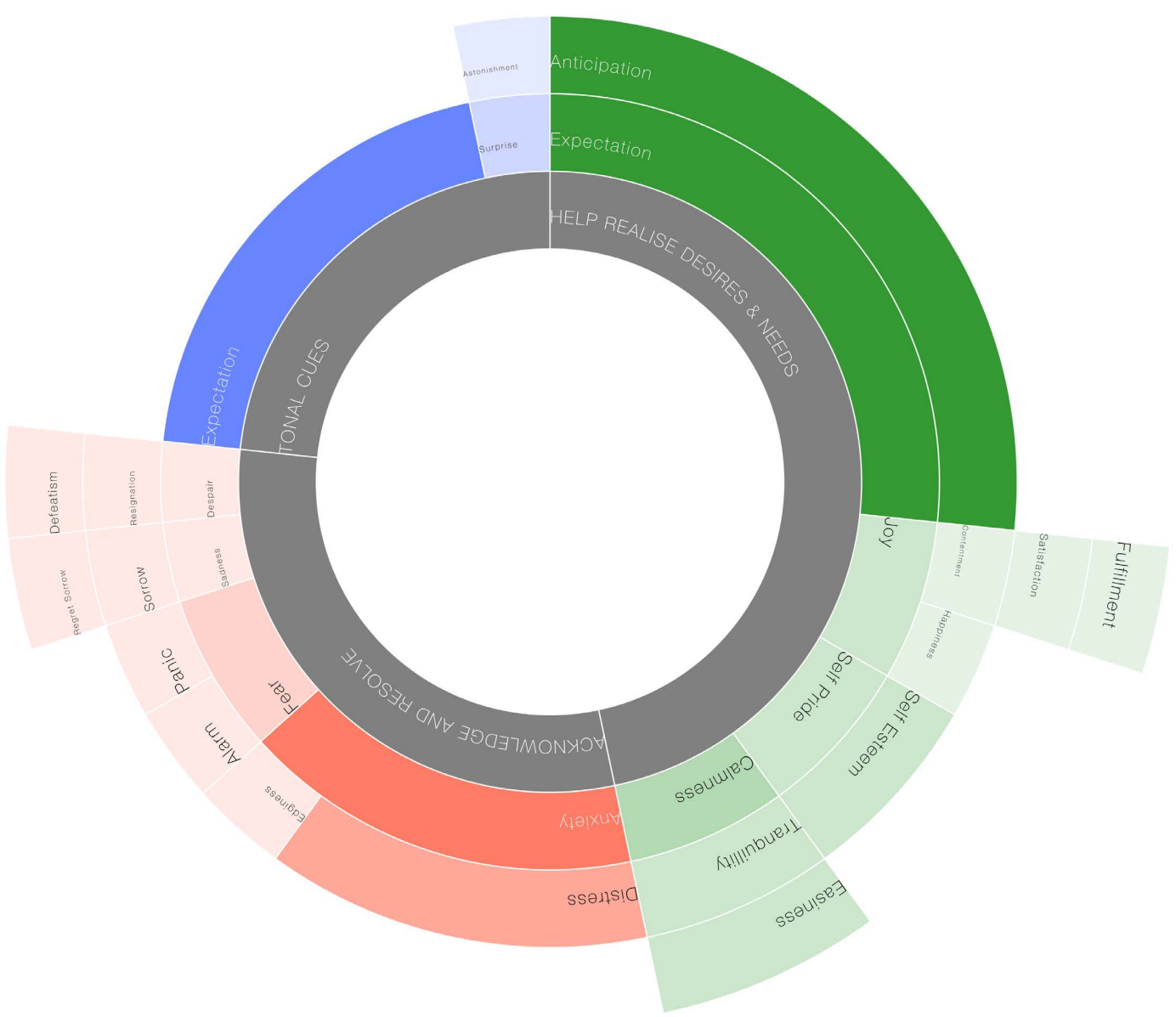

Figure 13. Wellness Japan: Affect June 2019. 

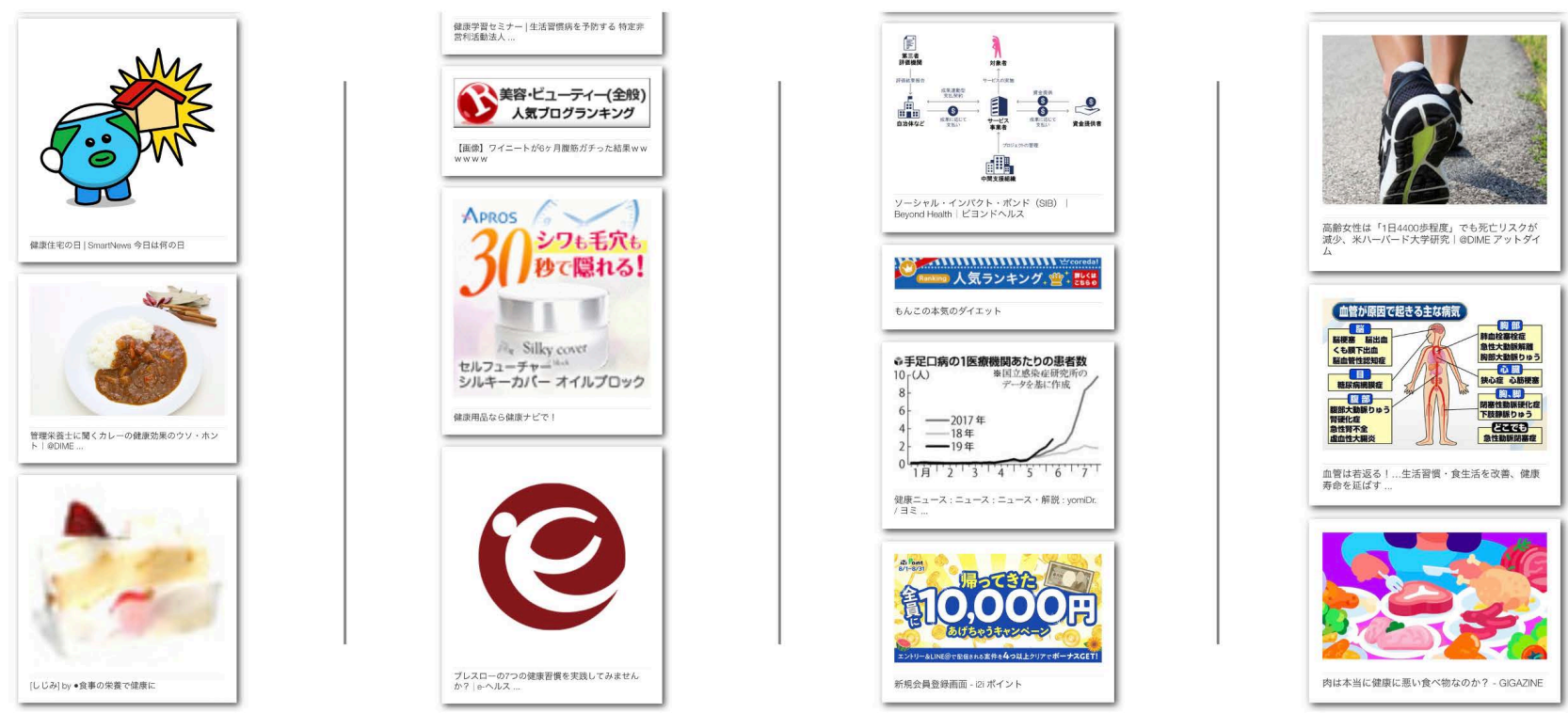

Figure 14. Wellness Japan: Powerful content, June 2019.

engagement but only average definition. There is some understanding, and existing content provides reasonable definition. Whilst we can learn from existing content creation, there is also space for novelty, that can capitalise on the strong pre-existing engagement. Content efficiency contrasts with content power, which is a measure of the power of individual pieces of content, to capture and to drive engagement with a narrative's core themes. This measure is independent of volume, reflective of the fact that traditional reach/frequency considerations of mass media power are inappropriate when evaluating digital media.

YouTube was noticeably the most influential media channel (Figure 15) indicative of the trend in the importance of video. In comparison, to the UK, the key topical drivers of engagement, in Japan, were much broader and more personal providing promotional and management themes for Wellness.

Wellness remained a timeless narrative in December 2019 (Figure 16). The uncertainty then, and related emotion (Figure 17) was driven by Brexit and by June 2020 the UK was singularly focused on the pandemic. After almost 4 months of the national lockdown in the UK, in broad terms the emotions associated with Wellness (Figure 18), and their relationships have apparently not changed substantively at the macro level. However, there has been a substantial shift in the driver regarding what is causing anxiety and fear for some and a sense of resignation and despair for others. The cause was different, and the scope of concerns were broader, beyond the personal, becoming now a mixture of personal and national, indeed international, in terms of their nature and extent (Figure 19).

In June 2020, in Japan, the Personal Friendship and Personal Bond narratives have both become transformational (Table 4). Moreover, the focus on family and community are heightened as they along with health/well-being and leisure/free time are timeless (Table 5). All narratives remain weak in terms of 


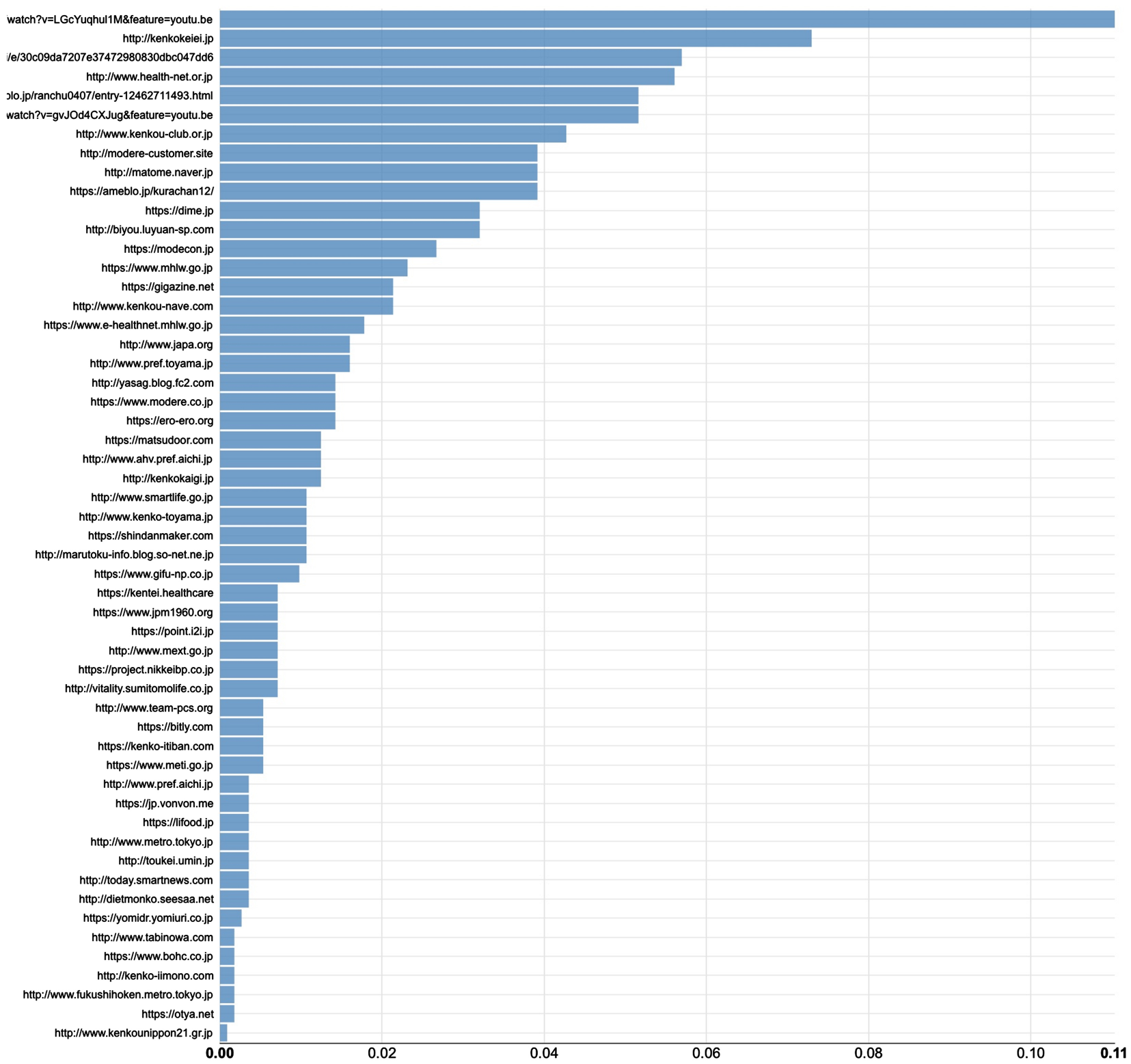

Figure 15. Wellness Japan: Media power, June 2019.

content efficiency, and not surprisingly many remain Transient, especially those relating to work, finance, and free time. Significantly, the affect around the Family, is both active and positive and despite being surprised and astonished by the situation there is a sense of calmness, love, and joy in the family unit. Covid-19 is first a human tragedy, and we are witnessing in this Virtual Living Lab universal human values of love, purpose, and connectivity uniting us. Although there are, at present, no clear topics, or themes, NHK is the key source of content. Indeed, it is fair to say that both Japanese and British now feel more connected to family, friends, and immediate neighbours.

The implications for the future, we should support the things that bind us together, and invest in our communities at scale. We can imagine that role of convenience stores will have the potential to become more integral to daily 


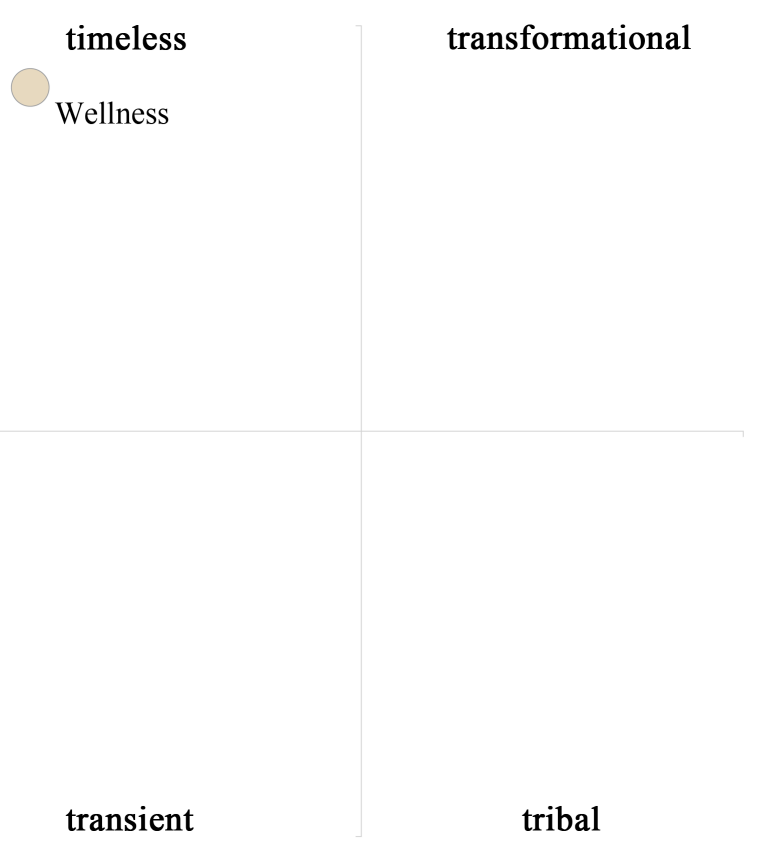

Figure 16. Wellness UK: Narrative categorization, December 2019.

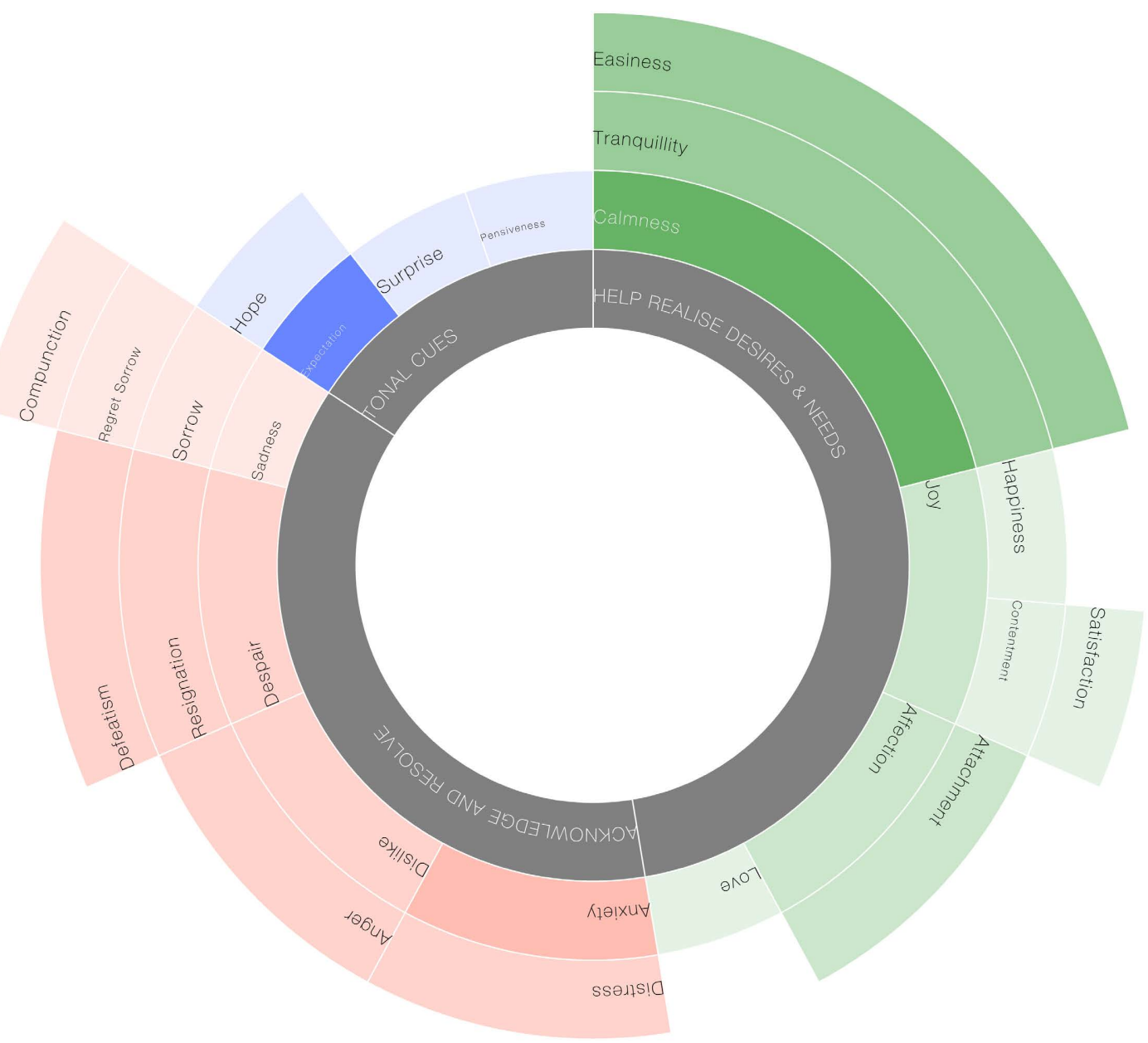

Figure 17. Wellness UK: Affect December 2019. 


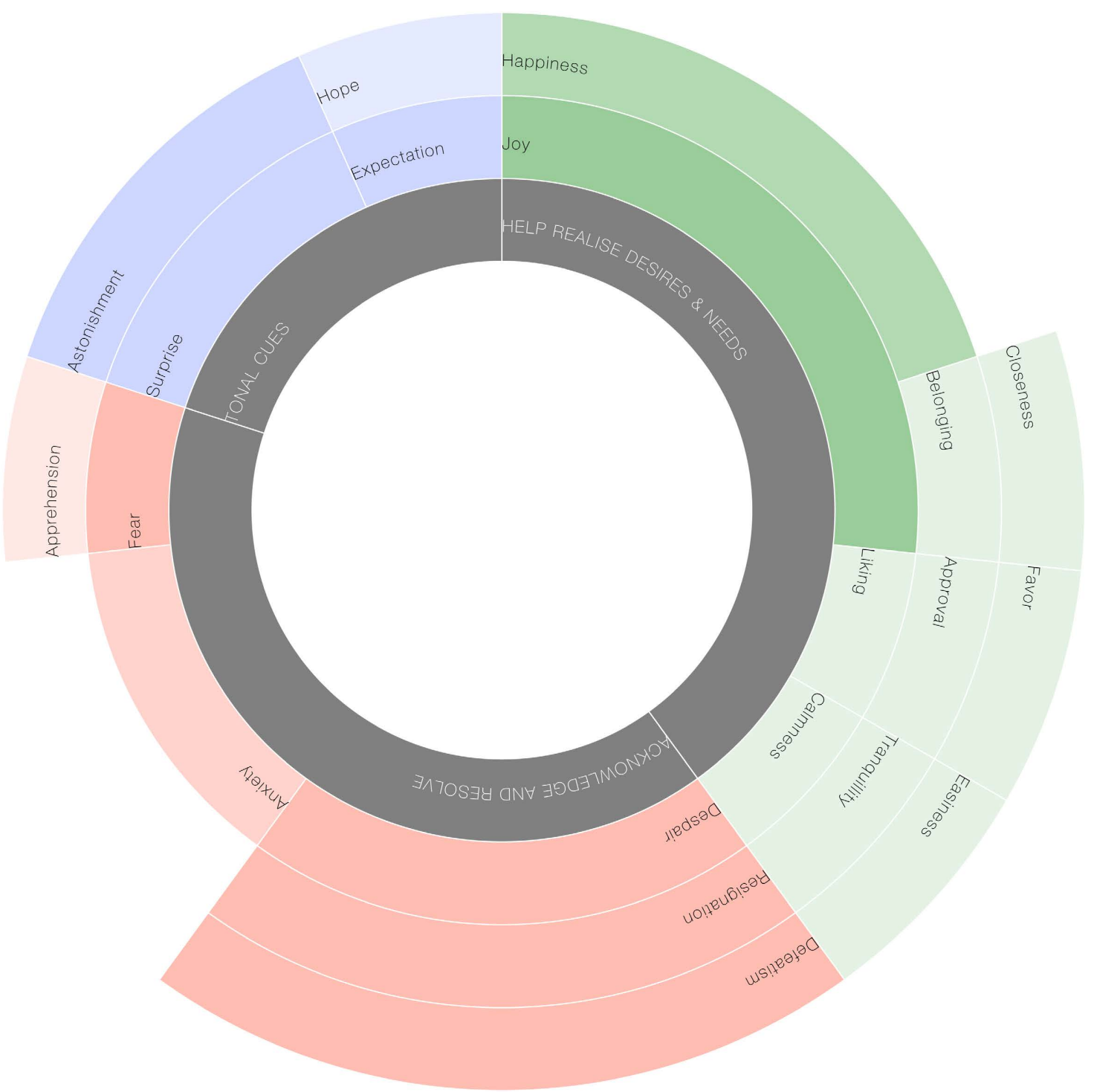

Figure 18. Wellness UK: Affect June 2020.

"community" living; less about casual shopping but more mainstream as people are now concerned about dining out and queueing in supermarkets. Furthermore, we might envision that cvs (convenience stores) will become more local and multiple types of layouts will become the norm.

By the end of the year, the situation in the UK had not materially changed (Figure 2 \& Figure 20) with fear and anxiety dominating any positive emotions. Before the (mid-) December 2020 wave of research with no vaccination roll-out in sight the focus of the Wellness narrative had become broader and more holistic (Figure 21), as families wondered if they would be able to escape the reality for a moment over the Christmas period. Traditional Wellness stories associated with yoga, serenity, and escape, were coupled with healthy food considerations, and the need to find a balance since Working From Home, for example, led to a sense of being “always on”. 


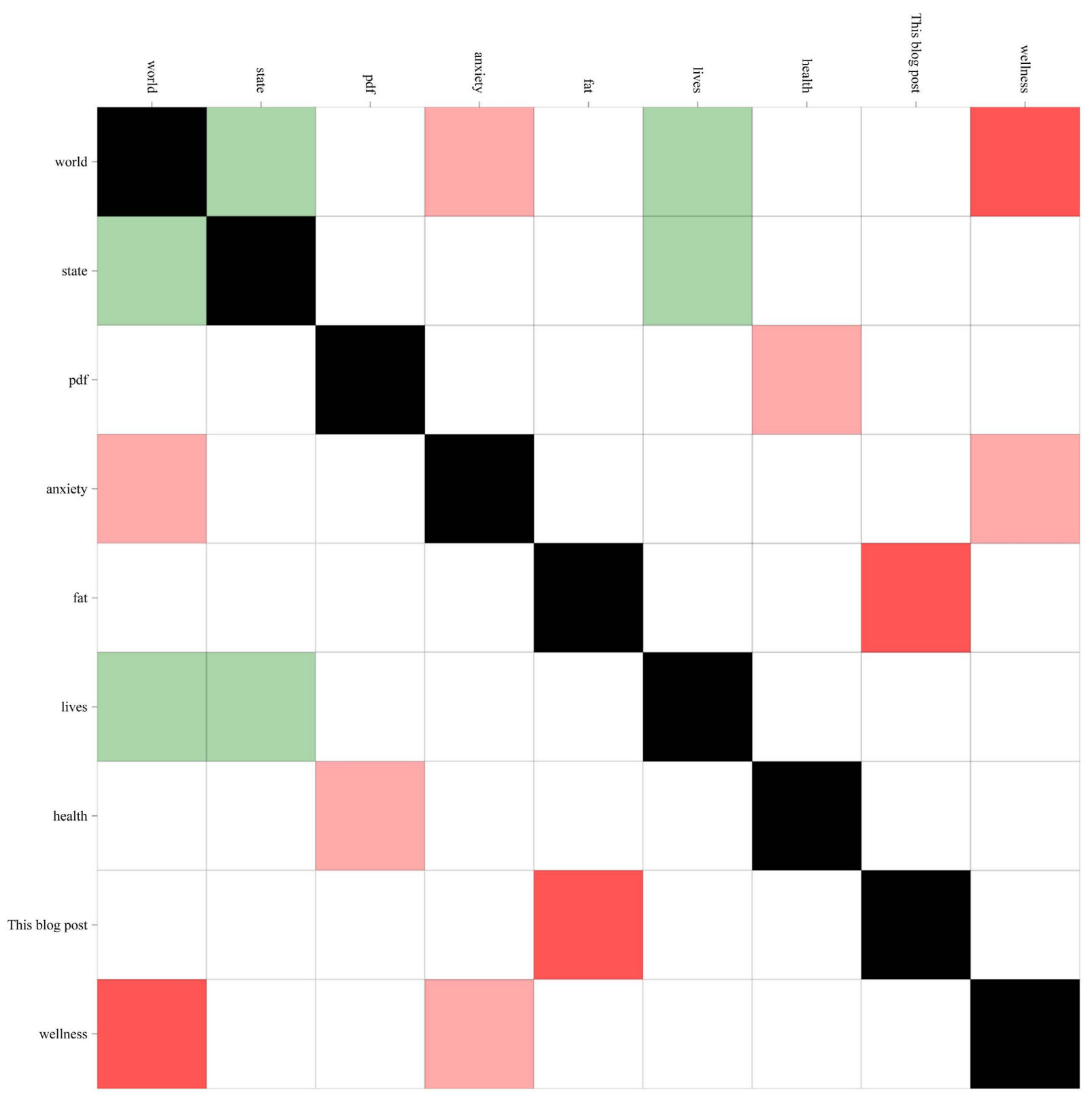

Figure 19. Wellness UK: Key topics and relationships, June 2019.

In June 2021, Wellness remains strongly timeless, but the efficiency of the content could be improved. The existing content provides reasonable definition, but while there are opportunities to learn from existing content creation there remains an opportunity for some novelty and innovation that can leverage this strong, pre-existing engagement. This is particularly true since they affect orientation is driven by an active and positive engagement, with momentum. While the emotional response remains broadly negative, there is a clear tonality (purple in Figure 22) to the emotions with expectation and surprise being heightened. This reflected the expectation that some of the lockdown measures being relaxed as the UK government indicated it was moving to Step 4 of its roadmap in July 2021 (GOV.UK, 2021). This was timed to coincide with the summer school 


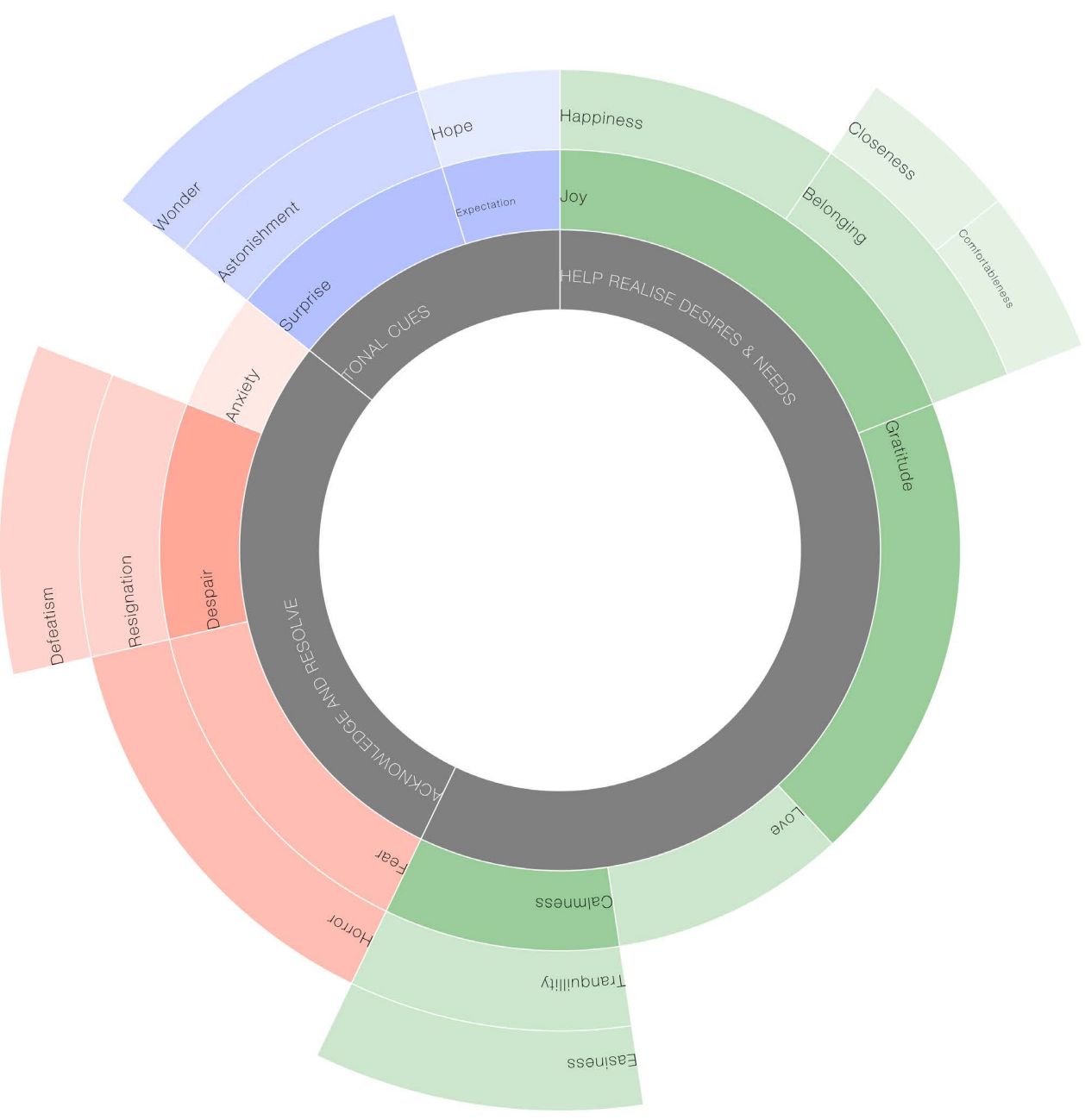

Figure 20. Wellness UK: Affect December 2020.
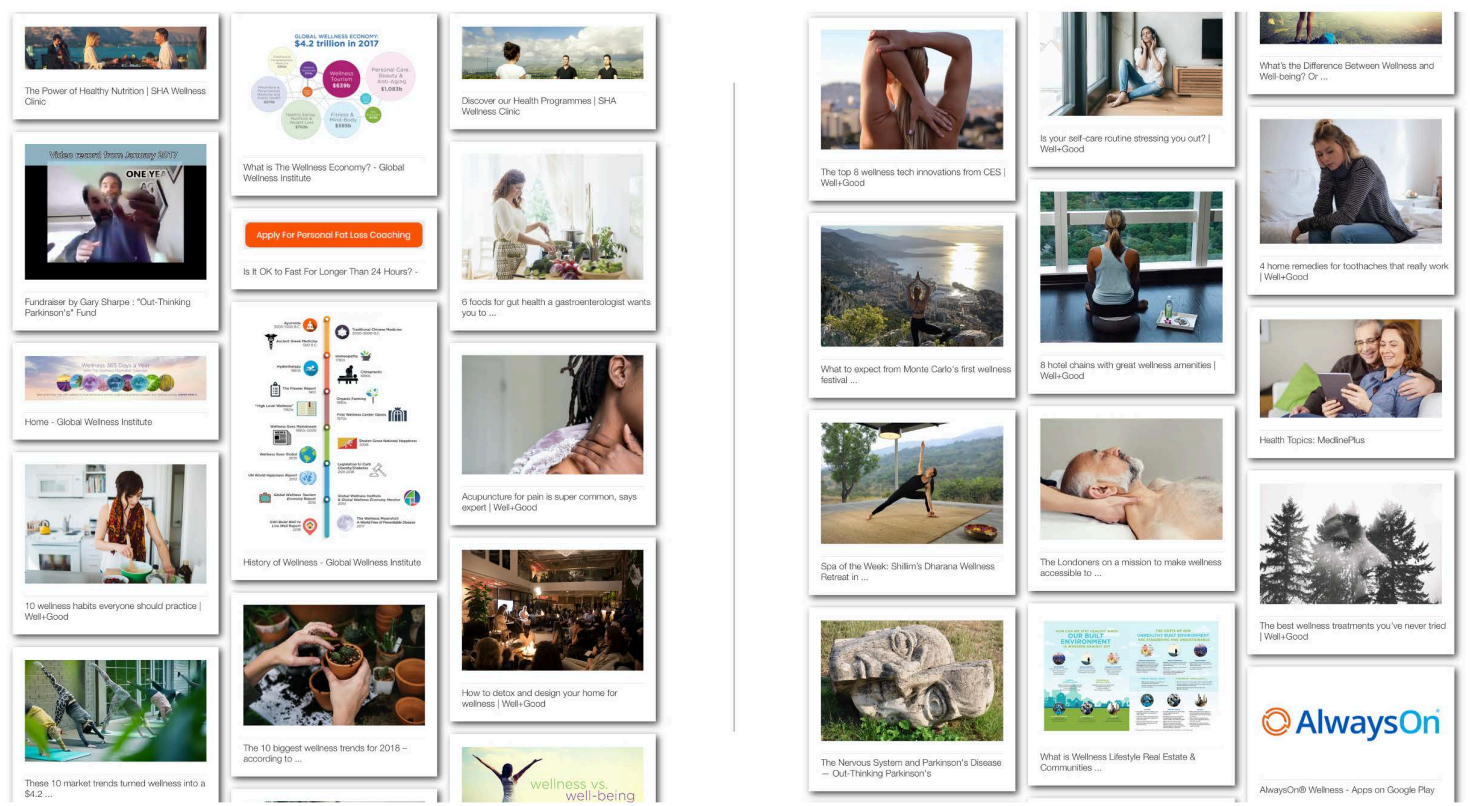

Figure 21. Wellness UK: Powerful content, December 2019. 


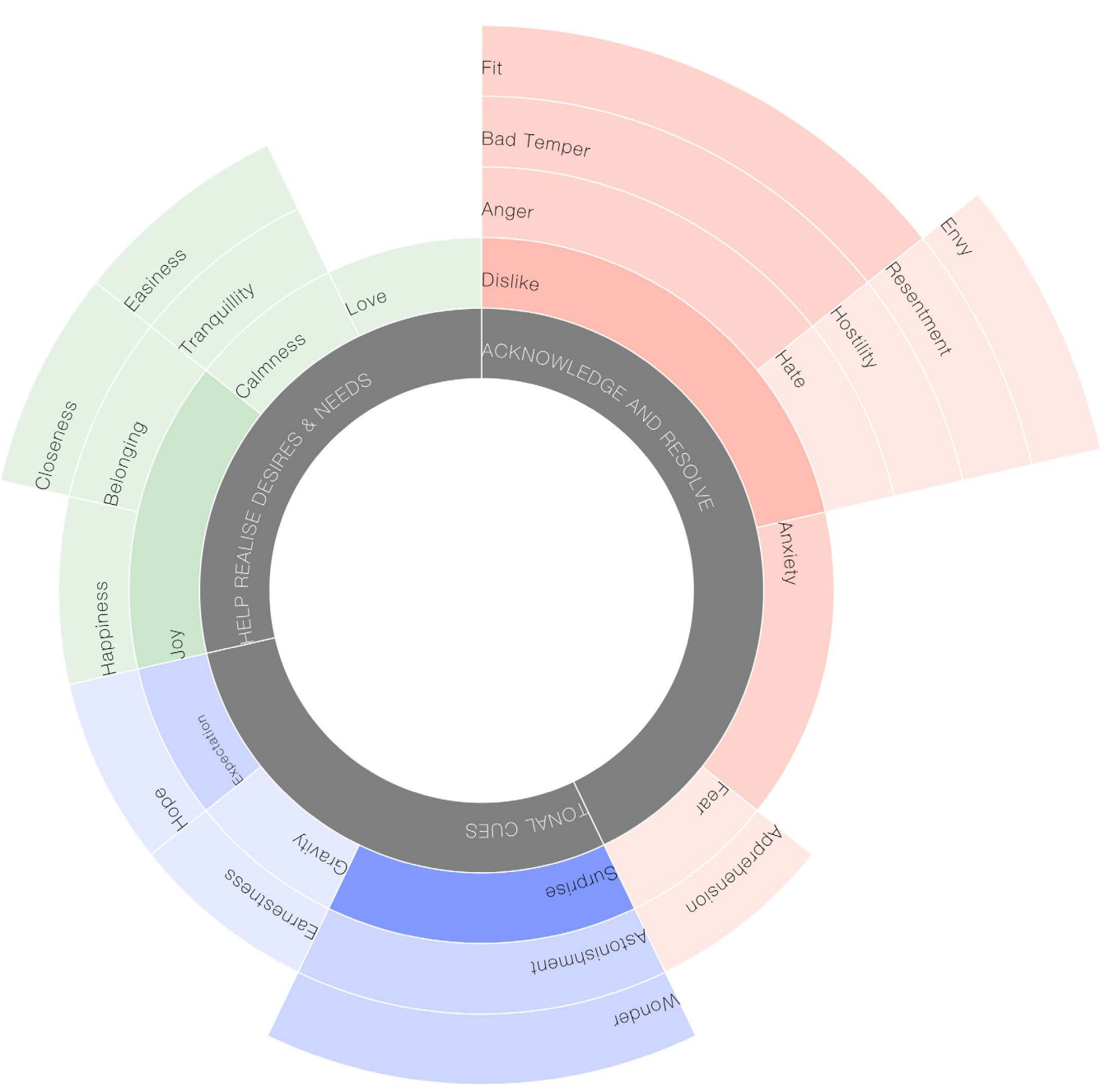

Figure 22. Wellness UK: Affect June 2021.

holidays when it was assumed that more outdoor activities were possible and pressure on the NHS was likely to be less than in winter.

\section{New Ways of Thinking and Communicating}

\subsection{Conclusions}

We are living in unprecedented and dynamic times questioning some fundamental norms, so is important to be able to understand and monitor what is important to people, now. Measuring and interpreting social and linguistic signals, by accessing openly available online content, is naturally more directly reflective of human behavior, than traditional market research. It can help you understand what is significant from a market's perspective and can be undertaken on a regular basis, as frequently as necessary, to assess the mood of the society, and to empower a focused, relevant, and credible response. It is self-evident more effective and efficient to engage with engagement that is already present. Shiller (2019) has eloquently shown that the public's subjective perceptions that go viral can shape economic trends. 
The recovery will not be a straight line, nor will it be on the same timetable in different countries/regions. There is a need for optimism as we evolve from DCàAC. There must be a positive tone to the messages and transformative collaboration can lead to improvements in QOL and productivity. Many people will remain cautious about returning to activities that have close human proximity, so we can't be frustrated by heightened attention to risk management. There will be a spectrum of behavior.

Healthcare future is going to be increasingly preventative, personalised and precise. Mobile apps, genetic testing, 3D printing and advanced screenings are just some of the new technologies producing biometric data on an unprecedented scale. As an adjunct this paper has focused on a new way of thinking and communicating since social considerations and the translation of invention to innovation demands improved engagement and clear communications to enhance the diffusion of ideas that can enhance QOL and improve life satisfaction.

Health has moved to the top of everyone's agenda as the pandemic has fundamentally, and permanently, changed how people live, work and what is important to them. In terms of technology transformation, covid-19 has in many regards fast-forwarded our futures. Digitization, data analytics will increase predictive analysis to be used to personalize healthcare and there will be greater consumerisation of the (contactless) patient experience, only further heightening healthy lifestyle choices. Streamlining will be much more important and so we need to simplify as people will reject the complex. Public and private institutions will need to accelerate digital investments and participation in ecosystems, where aligning with the narratives in our digital ecosystems, is likely to become much more important, and aid how we evolve the agile practices adopted during the crisis.

This paper has illustrated how it is possible, for the first time, with the Significance Systems methodology, to identify, and understand the key drivers of engagement and the Life Satisfaction and well-being narratives that would impact key drive constituencies and orient public opinion to effect change. Landscape was chosen due to its ability to first discover, then describe topical engagement. It showed that the narratives adopted had the potential, in both Japan and the UK, to drive engagement. These timeless narratives provide an authentic perspective that different stakeholders can align with to effect LifeStyle by Design. At present, while there were significant differences when comparing Japan and the UK, it was consistently found that the narratives were ill-defined. That said, the analyses in the paper demonstrated, in a preliminary manner, how and where powerful and motivating communications can help "shape the narratives that can shape the world".

\subsection{Imagineering}

This reframing of healthcare for society demands an improved level of health literacy amongst the population and this can be assisted by a focus on engaging 
with engagement over traditional messaging. Covid-19 has been attitudinal transformational, an equaliser, in that people are now talking more about mental health and seeking treatment when they would not have done before. While attitudes and behaviour have been changed by the pandemic, beyond our ability to communicate what people find important, it is also necessary to recognize that the vernacular has also been disrupted (Katermina \& Yachenko, 2020). There is a need to create a momentum, and public and private institutions will need to accelerate digital investments and participation in ecosystems, where aligning with Lifestyle narratives is likely to become more influential and impactful.

The imperative to communicate and really connect is to ensure that the complex is simplified. Traditional, mass media approaches are no longer fit for purpose. That said, since most narratives are transient this is also indicative that not all screen time/social media are productive time. Creating healthy, productive social media user experiences has become topical given the increasing reliance of social media and social sharing due to social distancing.

As people evolve from $\mathrm{DC}$ to $\mathrm{AC}$, they are looking forward to experimenting with newer activities. The pandemic has brought forward people's expectations in technology and innovation, as well as a desire to streamline their lives. Companies that recognize the new nature of convenience and community will embrace mobility, contactless experiences, and social sharing to create dynamic, future-forward behaviours.

With many different people/institutions naturally trying to provide help and advice; the imperative is to focus on what is important to people, now. Their health literacy is inadequate for the demands of self-medication, never mind in the new reality created by covid-19. Trust is an imperative but that can be gained by talking and fueling the stories that are important. The pandemic has sparked innovation, whether a start-up or an established cross-border, MNC, today's digital ecosystems enable you to focus the right message, to the right people, and in the right context. Listening is so underrated, but with a focus on objectively understanding and leveraging important stories, public policy and commercial enterprise, leaders, alike can affect change for the good. Engaging with engagement can move people, and can move markets, that will enhance people's health and QOL. The critical characteristic to enhance QOL is presenting a positive attitude and a sense of personal empowerment, in context, with a relevant and authentic narrative that heightens engagement. This should be basis of creating strategic leadership narratives.

\section{Conflicts of Interest}

The authors declare no conflicts of interest regarding the publication of this paper.

\section{References}

Beaumont, C. D., \& Ricketts, J. (2020). A Significant Moment in History: A Virtual Living Lab. LifeStyle Narratives That Are Shaping Our World; The Cases of Japan and UK 
2019-2020. Sustainability, 12, Article No. 9658. https://doi.org/10.3390/su12229658

Bercovici, J. (2010). Who Coined 'Social Media'? Web Pioneers Compete for Credit. Forbes. https://www.forbes.com/sites/jeffbercovici/2010/12/09/who-coined-social-media-webpioneers-compete-for-credit/\#1fada0c151d5

Clark, A. E., Flèche, S., Layard, R., Powdthavee, N., \& Ward, G. (2018). The Origins of Happiness. Princeton University Press. https://doi.org/10.1515/9781400889129

Clark, K., \& Yamazaki, K. (2020). Designing Presence. In T. Ahram, R. Taiar, V. GremeauxBader, \& K. Aminian (Eds.), Human Interaction, Emerging Technologies and Future Applications II (pp. 3-9). Springer. https://doi.org/10.1007/978-3-030-44267-5 1

Edelman Trust Barometer (2021). Global Report. Online Fieldwork in 28 Countries between October 19th to November 18th 2020. https://www.edelman.com/trust/2021-trust-barometer

FT (2021, April 28). How Excess Deaths Compared around the World since the Covid Outbreaks begun, Coronavirus Tracker: The Latest Figures as Countries Fight the Covid-19 Resurgence.

Gans, J. (2020, November 11). A Hidden Success in the Covid-19 Mess: The Internet, Stat, First Opinion.

https://www.statnews.com/2020/11/11/a-hidden-success-in-the-covid-19-mess-the-int ernet/

Gelfand, M. J., Jackson, J. C., Pan, X., Nau, D., Nau, D., Pieper, D., Denison, E. et al. (2021). The Relationship between Cultural Tightness-Looseness and COVID-19 Cases and Deaths: A Global Analysis. Lancet Planet Health, 5, E135-E144. https://doi.org/10.1016/S2542-5196(20)30301-6

GOV.UK (2021, August 27). Guidance: Moving to Step 4 of the Roadmap. Cabinet Office. https://www.gov.uk/government/publications/covid-19-response-summer-2021-roadm ap/moving-to-step-4-of-the-roadmap

Hofstede, G. (2001). Culture's Consequences: Comparing Values, Behaviors, Institutions, and Organizations across Nations (2nd ed.). SAGE.

Huber, M. (2011). How Should We Define Health? BMJ, 343, Article No. d4163. https://doi.org/10.1136/bmj.d4163

Huber, M., van Vliet, M., Giezenberg, M., Winkens, B., Heerkens, Y., Dagnelie, P. C. et al. (2016). Towards a "Patient-Centred" Operationalisation of the New Dynamic Concept of Health: A Mixed Methods Study. BMJ Open, 6, Article No. e01009. https://doi.org/10.1136/bmjopen-2015-010091

IfG (Institute for Government) (2021). Timeline of UK Government Coronavirus Lockdowns, March 2020-July 2021. Institute for Government Analysis. https://www.instituteforgovernment.org.uk/charts/uk-government-coronavirus-lockdo wns

Joachimsthaler, E. (2020). The Interaction Field. Public Affairs.

Katermina, V., \& Yachenko, E. (2020). Axiology of COVID-19 as a Linguistic Phenomenon in English Mass Media Discourse. Advances in Journalism and Communication, 8, 59-67. https://doi.org/10.4236/ajc.2020.82005

Layard, R. (2020). Can We Be Happier? Evidence and Ethics. Pelican Books.

Marr, D. (1982). Vision: A Computational Investigation into the Human Representation and Processing of Visual Information. W. H. Freeman and Company. (MIT Press RePublished the Book with a Foreword from Shimon Ullman and an afterword from Tomaso Poggio in 2010) 
McLuhan, M., \& Foire Q. (1967). The Medium Is the Massage: An Inventory of Effects. Bantam Books.

Nelms, B. (2020, May 3). BC, DC and AC-The Heroes Rarely Mentioned. The Citizen.

Parsfield, M., Morris, D., Bola, M., Marcus, G., Yoshioka, M., Knapp, M. et al. (Eds.) (2015, October 28). Community Capital: The Value of Connected Communities. RSA, Action \& Research Centre.

Peterson, T. (2017). Healthspan Is More Important Than Lifespan, So Why Don't More People Know About It? Washington University in St. Louis, Institute for Public Health, Aging.

Pike, L. A., Beaumont, C. D., \& Clewett, A. J. (1981). Morbidity in an Urban General Practice. HMSO (Her Majesty's Stationery Office).

Riley, C. (2017). After the Mass-Age. Analo. (In English and Japanese).

Rogers, E. M. (2003). Diffusions of Innovation (5/e). Simon and Schuster. [Original edition 1962]

Sakamoto, H., Ishikane, M., Ghaznavi, C., \& Ueda, P. (2021). Assessment of Suicide in Japan during the COVID-19 Pandemic vs Previous Years. JAMA Network Open, 4, Article ID: e2037378. https://doi.org/10.1001/jamanetworkopen.2020.37378

Shiller, J. (2019). Narrative Economics: How Stories Go Viral and Drive Major Economic Events. Princeton University Press. https://doi.org/10.1515/9780691189970

Shiseido (2021, March). AR Filter from SHISEIDO MEN.

https://www.shiseido.co.jp/sw/beautyinfo/telebeauty/?inflowcd=etc etc 00091546

Significance Systems (2021). Big Data Analyses.

http://significancesystems.com/powerful-engagement-insight/

Sørensen, K., Van den Broucke, S., Fullam, J., Doyle, G., Pelikan, J., Slonska, Z. et al. (2012). Health Literacy and Public Health: A Systematic Review and Integration of Definitions and Models. BMC Public Health, 12, Article No. 80.

https://doi.org/10.1186/1471-2458-12-80

The Guardian (2021, January 12). English Covid Rules Have Changed 64 Times Since March, Says Barrister. The Guardian.

Toffler, A. (1970). Future Shock. Random House.

World Health Organization (WHO) (1948). Definition of Heath. Preamble to the Constitution of WHO as Adopted by the International Health Conference, New York, 19 June-22 July 1946; Signed on 22 July 1946 by the Representatives of 61 States (Official Records of WHO, No. 2, p. 100) and Entered into Force on 7 April 1948. 